\title{
The pharmacological effects of the thermostabilising (m23) mutations and intra and extracellular $(\beta 36)$ deletions essential for crystallisation of the turkey $\beta$-adrenoceptor
}

\author{
Jillian G. Baker • Richard G. W. Proudman • \\ Christopher G. Tate
}

Received: 15 April 2011 / Accepted: 18 April 2011 / Published online: 6 May 2011

(C) The Author(s) 2011. This article is published with open access at Springerlink.com

\begin{abstract}
The X-ray crystal structure of the turkey $\beta$ adrenoceptor has recently been determined. However, mutations were introduced into the native receptor that was essential for structure determination. These may cause alterations to the receptor pharmacology. It is therefore essential to understand the effects of these mutations on the pharmacological characteristics of the receptor. This study examined the pharmacological effects of both the $\mathrm{m} 23$ mutations and the $\beta 36$ deletions, both alone and then in combination in the $\beta 36-\mathrm{m} 23$ mutant used in the crystallisation and structure determination of the turkey $\beta$-adrenoceptor. Stable CHO-K1 cell lines were made of each of the receptor mutants and the affinity and efficacy of ligands assessed by ${ }^{3} \mathrm{H}-\mathrm{CGP} 12177$ whole cell ligand binding, ${ }^{3} \mathrm{H}-\mathrm{cAMP}$ accumulation, and CRE-SPAP gene transcription assays. The m23 mutations reduced affinity for agonists, partial agonists and neutral antagonists by about tenfold whilst the $\beta 36$ deletions alone had no effect on ligand affinity. Both sets of changes appeared to reduce the agonist activation of the receptor. Both the $\mathrm{m} 23$ and the $\beta 36$ receptors retained two active agonist-induced receptor conformations similar to that of the original $\mathrm{t} \beta$ trunc receptor. The combined $\beta 36-\mathrm{m} 23$ receptor bound ligands with similar affinity to the m23 receptor; however, agonist activation was only observed with a few agonists including the catecholamines. Although the
\end{abstract}

J. G. Baker $(\bowtie) \cdot$ R. G. W. Proudman

Institute of Cell Signalling, C Floor Medical School,

University of Nottingham,

Queen's Medical Centre,

Nottingham NG7 2UH, UK

e-mail: jillian.baker@nottingham.ac.uk

C. G. Tate

MRC Laboratory of Molecular Biology,

Hills Road,

Cambridge CB2 0QH, UK combination of mutations severely reduced the activation ability, the final crystallised receptor $(\beta 36-\mathrm{m} 23)$ was still a fully functional receptor capable of binding agonist and antagonist ligands and activating intracellular agonist responses.

Keywords $\beta$-adrenoceptor - Conformational thermostabilisation $\cdot$ Crystal structure $\cdot$ Secondary site $\cdot \mathrm{m} 23$ mutations $\cdot \beta 36$ deletions
Abbreviations
BRL37344
$\left(\mathrm{R}^{*}, \mathrm{R}^{*}\right)-( \pm)-4-[2-[(2-(3-$ chlorophenyl)-2- hydroxyethyl)amino]propyl]phenoxyacetic acid
BRL35135A (R*,R*)-[4-2-[[2-(3-Chlorophenyl)-2- hydroxyethyl]amino]propyl]phenoxy]-ace- tic acid methyl ester
CHO Chinese hamster ovary poxy)-benzimidazol-2-one
CGP12177 (-)-4-(3-tert-butylamino-2-hydroxypro-
CGP20712A 2-hydroxy-5-(2-[\{hydroxy-3-(4-[1-methyl- 4-trifluoromethyl-2-imidazolyl]phenoxy) propyl amino] ethoxy)benzamide
CL316243 disodium $(R, R)-5$-(2-[\{2-(3-chlorophenyl)- 2-hydroxyethyl $\}$-amino]propyl)-1,3-benzo- dioxole-2,2, dicarboxylate
CYP cyanopindolol
ICI118551 (-)-1-(2,3-[dihydro-7-methyl-1 $H$-inden-4- yl]oxy)-3-([1-methylethyl]-amino)-2-butanol
ICI215001 (S)-4-[2-hydroxy-3-phenoxypropylaminoe- thoxy]phenoxyacetic acid hydrochloride
L755507 4-[[(Hexylamino)carbonyl]amino]-N-[4-[2- [[(2S)-2-hydroxy-3-(4-hydroxyphenoxy) propyl]amino]ethyl]phenyl]-benzenesulfo- namide 
SDZ21009 4-[3-[(1,1-Dimethylethyl)amino]-2-hydroxypropoxy]-1 H-indole-2-carboxylic acid 1methylethyl ester

SPAP secreted placental alkaline phosphates

SR59230A 1-(2-Ethylphenoxy)-3-[[(1S)-1,2,3,4-tetrahydro-1-naphthalenyl]amino]-(2S)-2-propanol

$\mathrm{t} \beta$ trunc $\quad$ erythrocyte turkey $\beta$-adrenoceptor with a C-terminal truncation (Warne et al. 2008)

ZD2079 4-[2-[[(2R)-2-Hydroxy-2-phenylethyl]amino]ethoxy]-benzeneacetic acid hydrochloride

ZD7114 (S)-4-[2-Hydroxy-3-phenoxypropylaminoethoxy]-N-(2-methoxyethyl)phenoxyacetamide hydrochloride

\section{Introduction}

There are three turkey $\beta$-adrenoceptors (Baker 2010a). The first one described, commonly simply referred to as the turkey $\beta$-adrenoceptor (Bilezikian and Aurbach 1973a, b; Schramm et al. 1972), is a Gs-coupled G protein-coupled receptor (GPCR) that has recently been crystallised and its structure determined to $2.7 \AA$ resolution (Warne et al. 2008). Crystallisation required milligramme quantities of pure, homogenous receptor, in a single conformation, that was stable in detergent (Warne et al. 2009). The native turkey $\beta$-adrenoceptor, which is significantly more stable than the human $\beta_{1}$ adrenoceptor (Serrano-Vega and Tate 2009), was still too unstable in short chain detergents for crystallisation and it also contained flexible regions that would prevent the formation of well-diffracting crystals. Therefore, the receptor was modified in a series of stages to increase both its stability and to also reduce the amount of unstructured regions.

Initially, part of the very large C-terminus was deleted and a $\mathrm{C} 116 \mathrm{~L}$ mutation made to make the starting construct: $\mathrm{t} \beta$ trunc construct (Baker 2010a; Warne et al. 2008). Deletion of the N-terminus, made the $\beta 6$ construct, which significantly increased heterologous expression in the baculovirus expression systems (Warne et al. 2003). This $\beta 6$ construct was then modified, firstly by introducing 6point mutations to increase the thermostability (the $\mathrm{m} 23$ mutations; Serrano-Vega et al. 2008, Fig. 1b) and secondly residues in intracellular loop three, $\mathrm{C}$-terminus and the palmitoylation site were removed ( $\beta 36$ deletions; Warne et al. 2009, Fig. 1c). Combination of the receptor truncations ( $\beta 36$ deletions) and the thermostabilising mutations (m23 mutations) to form the construct $\beta 36-\mathrm{m} 23$ (Fig. 1d) allowed crystallisation and structure determination (Warne et al. 2008, 2009).

The turkey $\beta$-adrenoceptor has several characteristics similar to that of the human $\beta_{1}$-adrenoceptor. If the amino acid sequences are compared, there is $82 \%$ identity between the transmembrane regions of both receptors with all the residues essential for catecholamine binding being absolutely conserved (Warne et al. 2008). Certain pharmacological characteristics are also very similar between the two receptors. For example, CGP12177 is an agonist at both receptors and its responses are similarly resistant to inhibition by classical antagonists (Baker 2005a; 2010a; Konkar et al. 2000; Lowe et al. 2002). In addition, both receptors show a significant difference between their affinity $\left(K_{D}\right.$ value) for CGP12177 and its partial agonist $\mathrm{EC}_{50}$ value in functional assays (Baker et al. 2003, Baker 2010a; Konkar et al. 2000). Furthermore, several ligands appear to stimulate a two-component concentration response curve in both receptors, suggesting that they appear to exist in at least two agonist-induced conformations (Arch 2004; Baker et al. 2003, 2010a, b; Molenaar 2003; Walter et al. 1984). There are, however, a few notable differences between the receptors, for example the affinity of CGP20712A (a human $\beta_{1}$-selective adrenoceptor antagonist) and ICI118551 (a human $\beta_{2}$-selective antagonist) are similar at the turkey $\beta$-adrenoceptor ( $\mathrm{t} \beta$ trunc).

Structural information on GPCRs is very helpful in the field of drug discovery and GPCR structures will potentially assist in computer-aided drug design (Congreve and Marshall 2010). However, the mutations introduced into the native receptor that were essential for structure determination may cause alterations to the receptor pharmacology. Therefore, for the maximum benefit to be realised from the structure, it is essential to understand the effects of the mutations on the pharmacological characteristics of the receptor. Here, we examine in detail the pharmacological effects of both the $\mathrm{m} 23$ mutations and the $\beta 36$ deletions, both alone and in combination in the $\beta 36-\mathrm{m} 23$ mutant used in the crystallisation and structure determination of the turkey $\beta$-adrenoceptor (Warne et al. 2008). This study looks at the binding characteristics of both agonists and antagonists to assess affinity changes, functional assays to examine receptor ligand efficacy and an analysis of the two agonist conformations observed for some ligands.

\section{Methods}

\section{Materials}

Foetal calf serum which was from PAA Laboratories (Teddington, Middlesex, UK). Microscint 20 scintillation fluid from PerkinElmer (Shelton, CT, USA). ${ }^{3} \mathrm{H}-\mathrm{CGP} 12177$, ${ }^{3} \mathrm{H}$-adenine and ${ }^{14} \mathrm{C}$-cAMP were from Amersham International (Buckinghamshire, UK). Betaxolol, bisoprolol, bucindolol, BRL37344, carvedilol, cimaterol, formoterol, ICI 215001, isoprenaline, L755507, salmeterol, SDZ21009, 


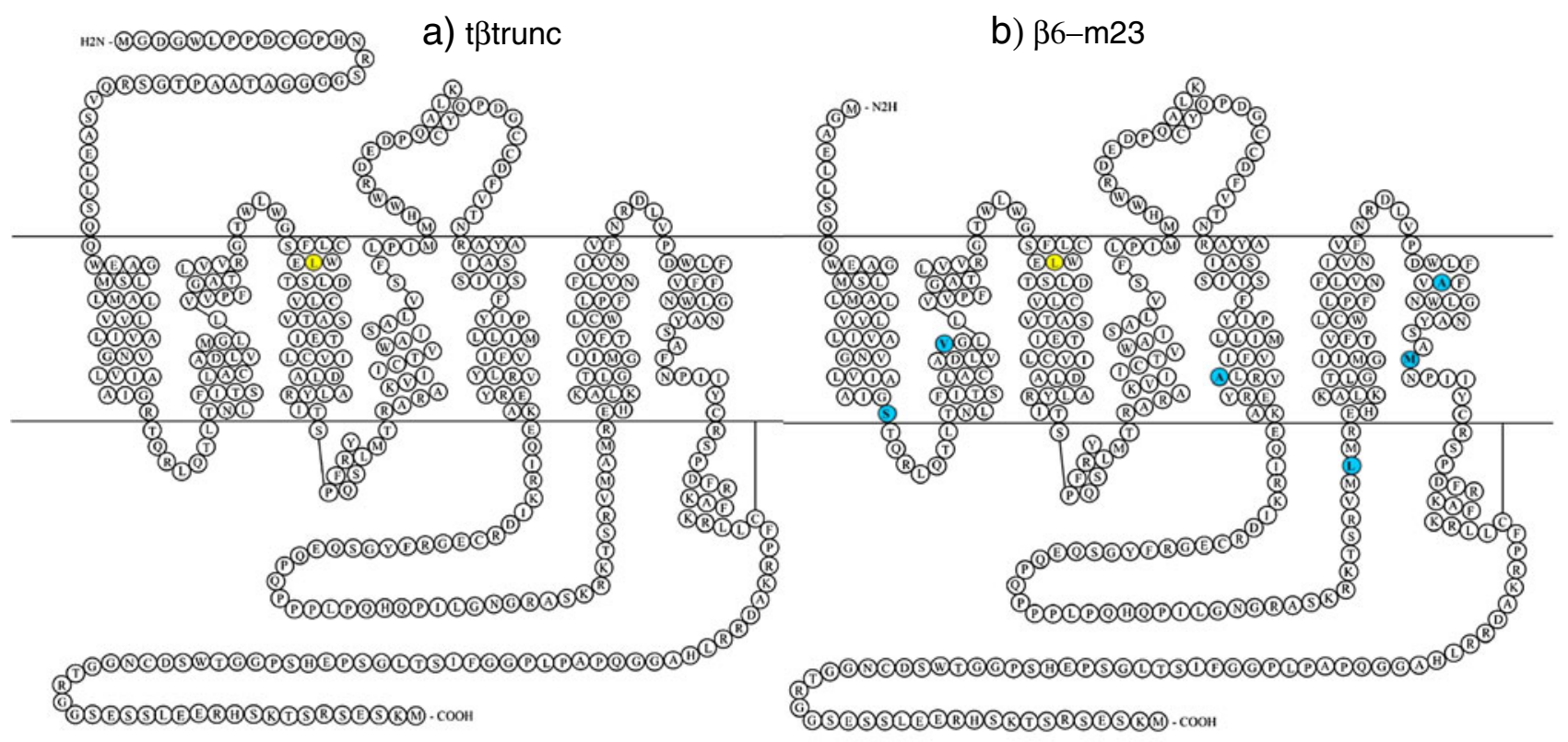

c) $\beta 36$

d) $\beta 36-\mathrm{m} 23$

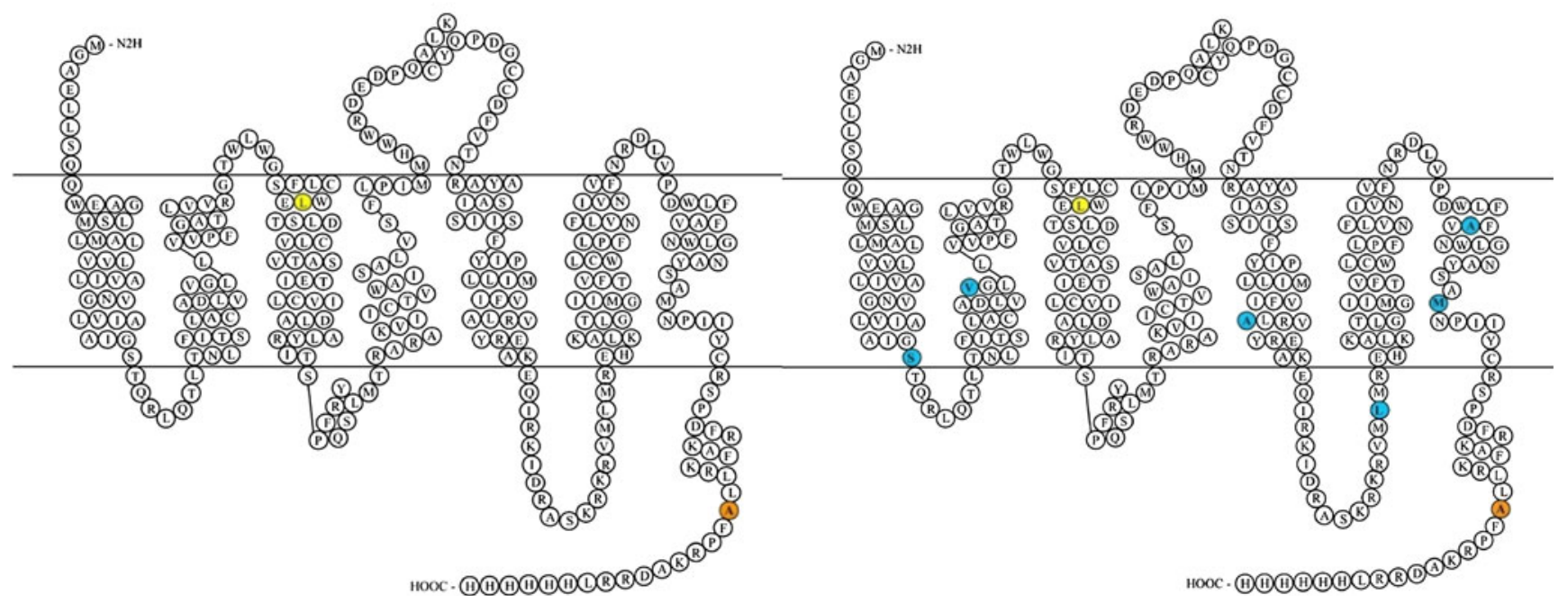

Fig. 1 The amino acid sequence of the turkey $\beta$-adrenoceptor after deletion of the $\mathrm{C}$-terminal 50 amino acid residues ( $\mathrm{t} \beta$ trunc) and the three other mutants, $\beta 6-\mathrm{m} 23, \beta 36$ and $\beta 36-\mathrm{m} 23$ used in this study.

SR59230A, ZD2079 and ZD7114 were from Tocris Life Sciences (Avonmouth, UK). Carazolol was from US Biological (Swampscott, MA, USA) nebivolol and butoxamine were a gift from Stefano Evangelista (Menarini Ricerche Spa, Florence, Italy); zinterol was a gift from Dr. Torsten Christ (Department of Pharmacology and Toxicology, Dresden University of Technology, Germany.). All other reagents were from Sigma Chemicals (Poole, Dorset, UK).

Constructs, cell lines and cell culture

As the full-length turkey $\beta$-adrenoceptor did not express (Baker 2010a), the starting point for this study
Thermostabilising point mutations are coloured blue, the original C116L mutation in yellow and the C358A mutation to remove the palmitoylation sites in orange

( $\mathrm{t} \beta$ trunc) was a $\mathrm{C}$-terminally truncated version of the turkey $\beta$-adrenoceptor that has 59 amino acids deleted from the C-terminus (residues 425-483) and one-point mutation C116L (Fig. 1a; Warne et al. 2008). This improved functional expression of the turkey $\beta$-adrenoceptor by threefold in the baculovirus expression system. In order to improve expression of the receptor for structural studies, 30 amino acid were deleted from the N-terminus (residues 2-32; construct $\beta 6$; Warne et al. 2003). The thermostability of the receptor was increased by the inclusion of 6 point mutations introduced into the receptor (R67S, M90V, Y227A, A282L, F327A, $\mathrm{F} 338 \mathrm{M}$ ), which are referred to as the $\mathrm{m} 23$ mutations (construct $=\beta 6-\mathrm{m} 23$; Serrano-Vega et al. 2008). This in- 
Table $1 \log K_{D}$ values obtained from ${ }^{3} \mathrm{H}-\mathrm{CGP} 12177$ whole cell binding studies in $\mathrm{CHO}$ cells stably expressing either the t $\beta$ trunc, $\beta 36, \beta 6-\mathrm{m} 23$ or $\beta 36-$ $\mathrm{m} 23$ adrenoceptors
Values represent mean \pm SEM for $n$ separate experiments

${ }^{a}$ The $\mathrm{t} \beta$ trunc data is taken from Baker (2010a)

\begin{tabular}{|c|c|c|c|c|c|c|c|}
\hline & $\mathrm{t} \beta$ trunc $^{\mathrm{a}}$ & $\beta 6-\mathrm{m} 23$ & $n$ & $\beta 36$ & $n$ & $\beta 36-\mathrm{m} 23$ & $n$ \\
\hline Acebutolol & -5.85 & $-4.91 \pm 0.05$ & 5 & $-5.81 \pm 0.06$ & 6 & $-4.72 \pm 0.07$ & 7 \\
\hline Adrenaline & -6.01 & $-3.81 \pm 0.07$ & 11 & $-5.88 \pm 0.04$ & 7 & $-3.88 \pm 0.08$ & 6 \\
\hline Alprenolol & -7.96 & $-7.40 \pm 0.05$ & 5 & $-8.09 \pm 0.02$ & 5 & $-7.35 \pm 0.07$ & 7 \\
\hline Atenolol & -5.40 & $-4.57 \pm 0.05$ & 5 & $-5.23 \pm 0.03$ & 6 & $-4.29 \pm 0.11$ & 6 \\
\hline Betaxalol & -6.90 & $-6.38 \pm 0.01$ & 5 & $-6.53 \pm 0.04$ & 6 & $-5.85 \pm 0.07$ & 6 \\
\hline BRL35135A & -6.32 & $-5.37 \pm 0.10$ & 5 & $-6.86 \pm 0.11$ & 5 & $-6.00 \pm 0.10$ & 5 \\
\hline BRL37344 & -5.19 & $-4.03 \pm 0.07$ & 5 & $-5.25 \pm 0.07$ & 6 & $-4.27 \pm 0.04$ & 6 \\
\hline Bisoprolol & -6.70 & $-5.66 \pm 0.05$ & 5 & $-6.37 \pm 0.05$ & 6 & $-5.38 \pm 0.04$ & 6 \\
\hline Bupranolol & -8.43 & $-7.78 \pm 0.04$ & 5 & $-8.42 \pm 0.05$ & 6 & $-7.61 \pm 0.08$ & 6 \\
\hline Bucindolol & -9.43 & $-8.71 \pm 0.02$ & 4 & $-9.39 \pm 0.07$ & 6 & $-8.56 \pm 0.08$ & 6 \\
\hline Butoxamine & -5.24 & $-4.93 \pm 0.07$ & 5 & $-5.22 \pm 0.06$ & 6 & $-4.78 \pm 0.10$ & 5 \\
\hline Carazolol & -10.20 & $-9.09 \pm 0.04$ & 13 & $-10.08 \pm 0.05$ & 6 & $-9.23 \pm 0.10$ & 6 \\
\hline Carvedilol & -9.43 & $-8.69 \pm 0.07$ & 5 & $-9.58 \pm 0.06$ & 5 & $-8.72 \pm 0.09$ & 5 \\
\hline CGP20712A & -7.53 & $-6.59 \pm 0.05$ & 11 & $-7.47 \pm 0.07$ & 8 & $-6.38 \pm 0.09$ & 8 \\
\hline Cimaterol & -7.17 & $-5.44 \pm 0.04$ & 8 & $-7.33 \pm 0.06$ & 9 & $-5.56 \pm 0.06$ & 9 \\
\hline CL316243 & $\geq 4$ & $\geq 4$ & 4 & $\geq 4$ & 6 & $\geq 4$ & 6 \\
\hline Clenbuterol & -6.74 & $-5.56 \pm 0.02$ & 5 & $-6.89 \pm 0.06$ & 6 & $-5.66 \pm 0.05$ & 6 \\
\hline S-Cyanopindolol & -10.89 & $-9.85 \pm 0.07$ & 12 & $-10.81 \pm 0.07$ & 6 & $-10.01 \pm 0.11$ & 6 \\
\hline Denopamine & -6.29 & $-5.13 \pm 0.04$ & 7 & $-6.29 \pm 0.05$ & 7 & $-4.99 \pm 0.06$ & 6 \\
\hline Dobutamine & -5.69 & $-5.40 \pm 0.01$ & 5 & $-5.74 \pm 0.06$ & 6 & $-5.49 \pm 0.03$ & 6 \\
\hline Fenoterol & -6.36 & $-4.33 \pm 0.04$ & 6 & $-6.33 \pm 0.06$ & 6 & $-4.55 \pm 0.10$ & 8 \\
\hline Formoterol & -7.33 & $-5.32 \pm 0.07$ & 6 & $-7.42 \pm 0.07$ & 6 & $-5.58 \pm 0.07$ & 6 \\
\hline ICI118551 & -7.20 & $-6.69 \pm 0.03$ & 5 & $-7.16 \pm 0.04$ & 6 & $-6.35 \pm 0.03$ & 6 \\
\hline ICI215001 & -5.79 & $-5.40 \pm 0.06$ & 6 & $-5.68 \pm 0.05$ & 6 & $-4.96 \pm 0.07$ & 7 \\
\hline Isoprenaline & -6.86 & $-5.13 \pm 0.05$ & 7 & $-6.67 \pm 0.13$ & 7 & $-5.16 \pm 0.05$ & 7 \\
\hline Labetolol & -7.51 & $-6.48 \pm 0.03$ & 5 & $-7.49 \pm 0.04$ & 6 & $-6.48 \pm 0.07$ & 6 \\
\hline L755507 & -7.17 & $-7.00 \pm 0.06$ & 6 & $-7.40 \pm 0.06$ & 7 & $-6.96 \pm 0.07$ & 6 \\
\hline Metaproterenol & -5.64 & $-3.57 \pm 0.03$ & 6 & $-5.71 \pm 0.08$ & 6 & $-3.49 \pm 0.08$ & 5 \\
\hline Metoprolol & -6.42 & $-5.68 \pm 0.03$ & 6 & $-6.10 \pm 0.05$ & 7 & $-5.27 \pm 0.07$ & 7 \\
\hline Nadolol & -7.99 & $-7.33 \pm 0.02$ & 5 & $-7.98 \pm 0.03$ & 6 & $-7.08 \pm 0.09$ & 6 \\
\hline Noradrenaline & -6.60 & $-4.40 \pm 0.03$ & 6 & $-6.29 \pm 0.05$ & 7 & $-4.53 \pm 0.11$ & 7 \\
\hline Nebivolol & -8.25 & $-8.01 \pm 0.01$ & 4 & $-8.35 \pm 0.05$ & 6 & $-7.73 \pm 0.09$ & 6 \\
\hline Pindolol & -8.55 & $-7.92 \pm 0.06$ & 5 & $-8.56 \pm 0.06$ & 6 & $-8.01 \pm 0.05$ & 6 \\
\hline Pronethalol & -6.85 & $-6.11 \pm 0.03$ & 5 & $-6.93 \pm 0.04$ & 6 & $-6.12 \pm 0.08$ & 6 \\
\hline Propranolol & -8.51 & $-7.92 \pm 0.05$ & 6 & $-8.59 \pm 0.05$ & 7 & $-7.78 \pm 0.07$ & 7 \\
\hline Ractopamine & -6.75 & $-5.82 \pm 0.06$ & 6 & $-6.85 \pm 0.03$ & 6 & $-5.71 \pm 0.10$ & 6 \\
\hline Salbutamol & -4.99 & $-4.16 \pm 0.06$ & 6 & $-5.35 \pm 0.06$ & 6 & $-4.20 \pm 0.07$ & 6 \\
\hline Salmeterol & -5.92 & $-5.31 \pm 0.05$ & 7 & $-6.36 \pm 0.08$ & 8 & $-5.51 \pm 0.06$ & 6 \\
\hline SDZ21009 & -9.27 & $-8.57 \pm 0.06$ & 5 & $-9.41 \pm 0.04$ & 6 & $-8.62 \pm 0.08$ & 6 \\
\hline SR59230A & -7.39 & $-7.10 \pm 0.05$ & 6 & $-7.81 \pm 0.06$ & 7 & $-7.50 \pm 0.10$ & 7 \\
\hline Sotalol & -6.14 & $-5.47 \pm 0.03$ & 5 & $-6.06 \pm 0.05$ & 6 & $-5.21 \pm 0.05$ & 6 \\
\hline Terbutaline & -4.61 & $\geq 3$ & 3 & $-5.07 \pm 0.08$ & 6 & $\geq 3$ & 5 \\
\hline Timolol & -8.76 & $-7.95 \pm 0.03$ & 5 & $-8.90 \pm 0.04$ & 5 & $-7.82 \pm 0.05$ & 6 \\
\hline Tulobuterol & -5.60 & $-4.82 \pm 0.03$ & 5 & $-5.69 \pm 0.08$ & 7 & $-5.00 \pm 0.10$ & 6 \\
\hline Xamoterol & -6.58 & $-5.42 \pm 0.03$ & 6 & $-6.60 \pm 0.05$ & 6 & $-5.27 \pm 0.09$ & 6 \\
\hline ZD2079 & -3.77 & $\geq 4$ & 4 & $-4.15 \pm 0.07$ & 3 & $\geq 4$ & 6 \\
\hline ZD7114 & -7.30 & $-6.55 \pm 0.04$ & 5 & $-7.07 \pm 0.04$ & 6 & $-6.28 \pm 0.08$ & 6 \\
\hline Zinterol & -6.40 & $-5.42 \pm 0.05$ & 6 & $-6.52 \pm 0.06$ & 6 & $-5.40 \pm 0.06$ & 6 \\
\hline
\end{tabular}


creased the thermostability of the receptor and its tolerance to short-chain detergents by increasing kinetic barriers to the unfolded state (Balaraman et al. 2010; Serrano-Vega et al. 2008). The second round of changes involved removing potentially disordered flexible regions from the intracellular portion of the receptor. As well as the 30 amino acid deletion from the N-terminus ( $\beta 6$ construct), 30 amino acids were also deleted from the third intracellular loop (residues 244-271 and 277-278), a further 56 amino acids deleted from the C-terminus (residues 369 424) and a point mutation C358A introduced to remove the palmitoylation site (Warne et al. 2009). These are known as the $\beta 36$ deletions (construct $=\beta 36$; Warne et al. 2009 ). Both of these sets of changes were then combined into the final product $(\beta 36-\mathrm{m} 23)$ from which the X-ray crystal structure was determined (Fig. 1; Warne et al. 2008, 2009). Each of these constructs were then transfected into a Chinese hamster ovary $\mathrm{K} 1$ cells (CHO-K1) cell line stably expressing a six cAMP response element - secreted placental alkaline phosphatise reporter (CRE-SPAP) reporter gene using Lipofectamine and OPTIMEM as per manufacturer's instructions and a stable cell line of each mutation made by dilution cloning.

In order to check that there were no significant changes in the pharmacology of the receptor during the generation of the stable cell lines, CHO-K1 cells were also transiently transfected with each receptor construct and the binding of ligands examined under transient conditions (initial binding experiments only, see "Results" section). Here, the parent CHO-SPAP cells were transfected on day 1, the transfection reagents removed and replaced with media on day 2 , the cells plated in to white-sided 96-well plates on day 3 and a binding assay performed on day 4 .

All cell lines were grown in Dulbecco's modified Eagle's medium nutrient mix F12 containing 10\% foetal calf serum and $2 \mathrm{mM}$ L-glutamine in a $37^{\circ} \mathrm{C}$ humidified $5 \% \mathrm{CO}_{2}: 95 \%$ air atmosphere.

\section{${ }^{3} \mathrm{H}-\mathrm{CGP} 12177$ whole cell binding}

Cells were grown to confluence in white-sided tissue culture treated 96-well view plates. ${ }^{3} \mathrm{H}-\mathrm{CGP} 12177$ whole cell competition binding was performed as previously described (Baker 2005b) using ${ }^{3} \mathrm{H}-\mathrm{CGP} 12177$ in the range of $0.932-3.030 \mathrm{nM}$ (total volume $200 \mu \mathrm{l}$ per well). For saturation experiments, concentrations of ${ }^{3} \mathrm{H}-\mathrm{CGP} 12177$ in the range of $0.004-50.41 \mathrm{nM}$ were used. The receptor expression level of the $\beta 6-\mathrm{m} 23$ line was significantly higher than the other three cell lines, thus potentially posing a problem of ligand depletion. The total well volume to surface area of cells was therefore increased by carrying out an identical method, across all four cell lines, in 24-well plates (total volume of $2 \mathrm{ml}$ per well) and 48-well plates (total volume per well of $1.6 \mathrm{ml}$ ). For each individual cell line, the different methods yielded similar $K_{D}$ values ${ }^{3} \mathrm{H}$ CGP 12177, suggesting that ligand depletion was not a major factor. The results presented are therefore the mean \pm SEM of the results from whole cell binding carried out in 24-, 48- and 96-well plates.

\section{CRE-SPAP production}

Cells were grown to confluence in clear plastic tissue culture treated 96-well plates and CRE-SPAP secretion into the media measured between 5 and $6 \mathrm{~h}$ after the addition of agonist as previously described (Baker 2010a).
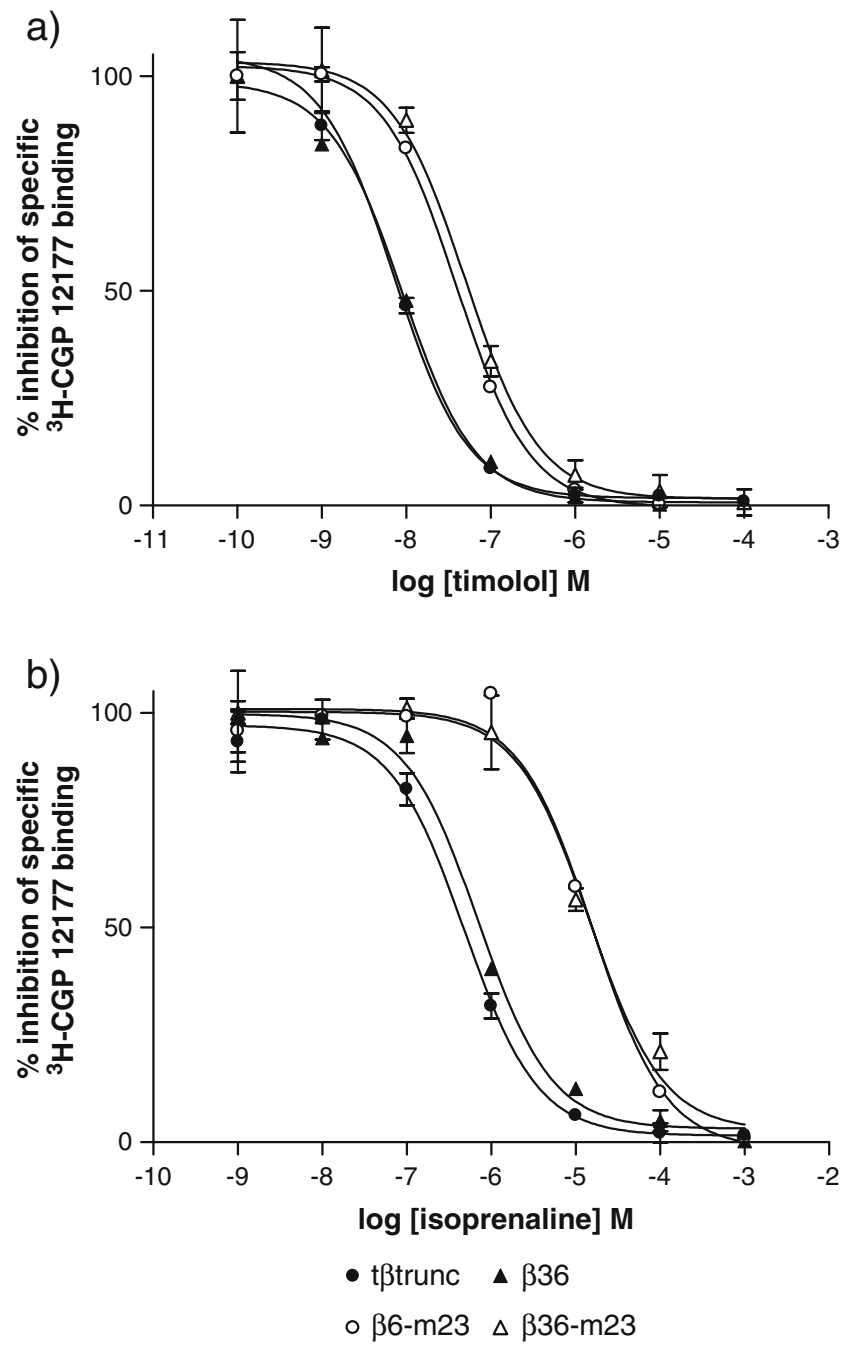

Fig. 2 Inhibition of ${ }^{3} \mathrm{H}-\mathrm{CGP} 12177$ specific binding to whole cells by a the antagonist timolol and $\mathbf{b}$ the agonist isoprenaline at each of the turkey $\beta$-adrenoceptors mutants. Nonspecific binding was determined by $10 \mu \mathrm{M}$ propranolol. The concentration of 3H-CGP 12177 present in these experiments was $1.6 \mathrm{nM}$. Data points are mean $\pm \mathrm{SE}$ mean of triplicate determinations. These single experiments are representative of $\mathbf{a}$ five and $\mathbf{b}$ seven separate experiments 


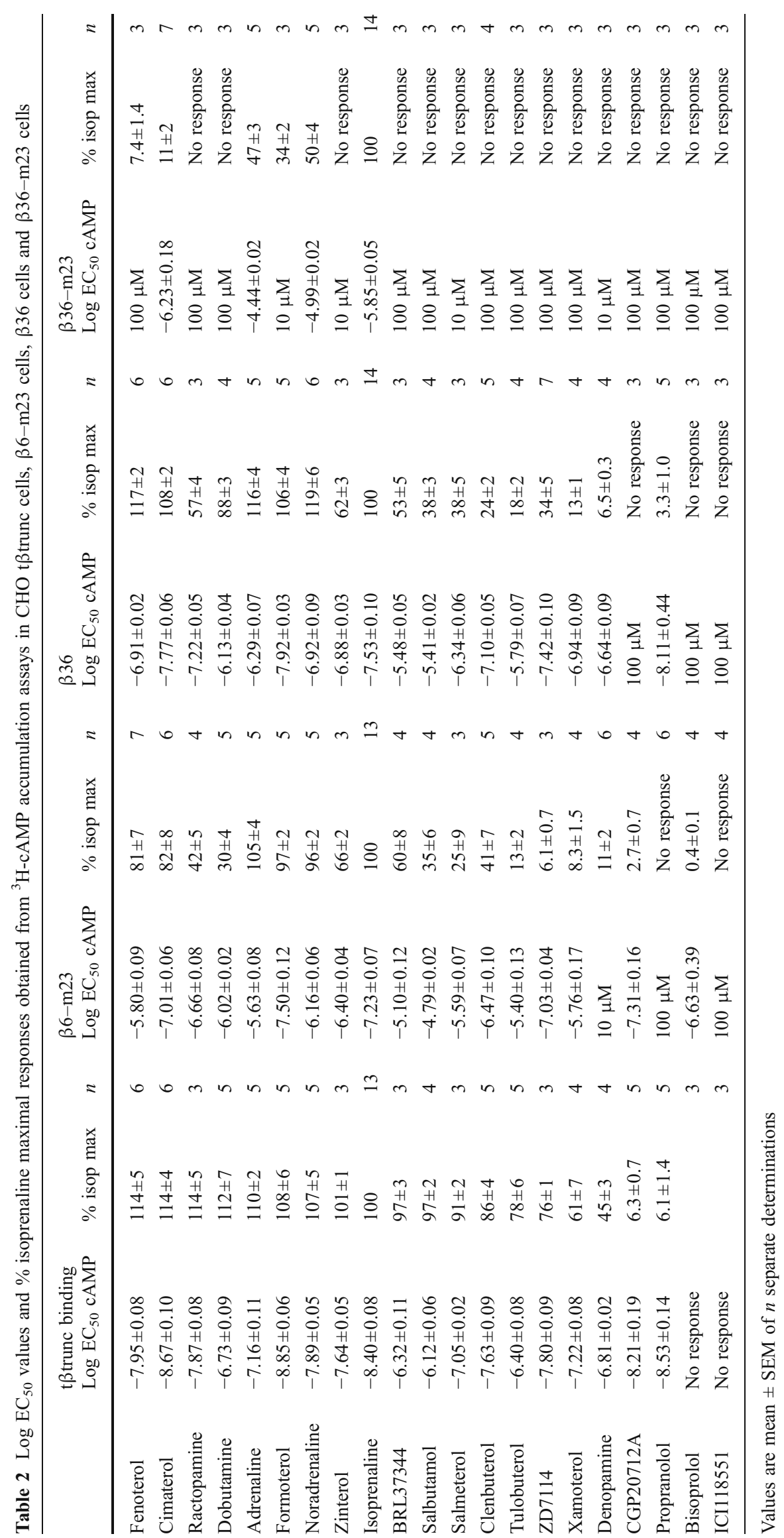


${ }^{3} \mathrm{H}-\mathrm{cAMP}$ accumulation

Cells were grown to confluence in clear plastic tissue culture treated 24-well plates. Following ${ }^{3} \mathrm{H}$-adenine pre-labelling, ${ }^{3} \mathrm{H}$-cAMP accumulation in the wells was measured as previously described (Baker 2010a). ${ }^{3} \mathrm{H}$-cAMP was separated from other ${ }^{3} \mathrm{H}$-nucleotides by sequential Dowex and alumina column chromatography as previously described (Donaldson et al. 1988).

\section{Data analysis}

Whole cell binding-saturation binding

Saturation binding curves of the total and nonspecific binding (as determined by the presence of $10 \mu \mathrm{M}$ propranolol) were performed in order to determine the specific binding $K_{D}$ value for ${ }^{3} \mathrm{H}-\mathrm{CGP} 12177$ and the receptor expression level. All data points on each binding curve were performed in quadruplicate. Specific binding (SB, Eq. 1) of ${ }^{3} \mathrm{H}-\mathrm{CGP} 12177$ at different concentrations of ${ }^{3} \mathrm{H}-$ CGP 12177 was fitted using the nonlinear regression programme Prism 2.01 to the equation:

$\mathrm{SB}=\frac{\left(A \times B_{\mathrm{MAX}}\right)}{\left(A+K_{D}\right)}$

where, $A$ is the concentration of ${ }^{3} \mathrm{H}-\mathrm{CGP} 12177, B_{\mathrm{MAX}}$ is the maximal specific binding and $K_{D}$ is the dissociation constant of ${ }^{3} \mathrm{H}-\mathrm{CGP} 12177$. Protein was determined by using a Pierce BCA Protein Assay Kit (Thermo Scientific, Rockford, USA) as per manufacturers' instructions.

Whole cell binding-competition binding

All data points on each binding curve were performed in triplicate and each 96-well plate also contained six

Table $3 \%$ isoprenaline maximal responses obtained from ${ }^{3} \mathrm{H}$-cAMP accumulation assays in $\mathrm{CHO}$ t $\beta$ trunc cells, $\beta 6-\mathrm{m} 23$ cells, $\beta 36$ cells and $\beta 36-\mathrm{m} 23$ cells, in response to a maximum concentration of ligand

\begin{tabular}{|c|c|c|c|c|c|c|c|c|c|}
\hline & Concentration used & $\begin{array}{l}\mathrm{t} \beta \text { trunc } \\
\% \text { isop max }\end{array}$ & $n$ & $\begin{array}{l}\beta 6-\mathrm{m} 23 \\
\% \text { isop max }\end{array}$ & & $\begin{array}{l}\beta 36 \\
\% \text { isop max }\end{array}$ & $n$ & $\begin{array}{l}\beta 36-\mathrm{m} 23 \\
\% \text { isop max }\end{array}$ & $n$ \\
\hline Metaproterenol & $100 \mu \mathrm{M}$ & $124 \pm 6$ & 4 & $92 \pm 3$ & 4 & $141 \pm 6$ & 4 & $6.1 \pm 0.3$ & 4 \\
\hline Terbutaline & $1 \mathrm{mM}$ & $120 \pm 3$ & 4 & $75 \pm 3$ & 4 & $100 \pm 4$ & 4 & $2.3 \pm 0.3$ & 4 \\
\hline BRL35135A & $10 \mu \mathrm{M}$ & $99 \pm 3$ & 4 & $81 \pm 4$ & 4 & $80 \pm 6$ & 4 & $12 \pm 1$ & 4 \\
\hline ICI215001 & $10 \mu \mathrm{M}$ & $75 \pm 3$ & 4 & $10 \pm 1$ & 4 & $33 \pm 3$ & 4 & No response & 4 \\
\hline ZD2079 & $100 \mu \mathrm{M}$ & $73 \pm 9$ & 4 & $25 \pm 2$ & 4 & $38 \pm 2$ & 4 & $0.4 \pm 0.1$ & 4 \\
\hline L755507 & $10 \mu \mathrm{M}$ & $59 \pm 8$ & 4 & $5 \pm 0.3$ & 4 & $10 \pm 1$ & 4 & No response & 4 \\
\hline Bucindolol & $10 \mu \mathrm{M}$ & $49 \pm 1$ & 4 & $17 \pm 1$ & 4 & $12 \pm 1$ & 4 & No response & 4 \\
\hline SR59230A & $1 \mu \mathrm{M}$ & $38 \pm 2$ & 4 & $1.4 \pm 0.1$ & 4 & $4.9 \pm 0.7$ & 4 & No response & 4 \\
\hline Pindolol & $10 \mu \mathrm{M}$ & $31 \pm 1$ & 4 & $1.5 \pm 0.1$ & 4 & $3.4 \pm 0.8$ & 4 & No response & 4 \\
\hline Alprenolol & $10 \mu \mathrm{M}$ & $31 \pm 2$ & 4 & $1.3 \pm 0.3$ & 4 & $4.9 \pm 0.8$ & 4 & No response & 4 \\
\hline Acebutolol & $100 \mu \mathrm{M}$ & $30 \pm 1$ & 4 & $1.2 \pm 0.2$ & 4 & $6.7 \pm 0.4$ & 4 & No response & 4 \\
\hline Labetolol & $100 \mu \mathrm{M}$ & $29 \pm 1$ & 4 & $6.1 \pm 0.6$ & 4 & $3.5 \pm 0.6$ & 4 & No response & 4 \\
\hline Pronethalol & $100 \mu \mathrm{M}$ & $29 \pm 1$ & 4 & $4.8 \pm 0.3$ & 4 & $2.4 \pm 0.7$ & 4 & No response & 4 \\
\hline SDZ21009 & $10 \mu \mathrm{M}$ & $24 \pm 1$ & 4 & $4.4 \pm 0.2$ & 4 & $3.7 \pm 0.3$ & 4 & No response & 4 \\
\hline Carvedilol & $10 \mu \mathrm{M}$ & $12 \pm 0.4$ & 4 & $0.6 \pm 0.1$ & 4 & No response & 4 & No response & 4 \\
\hline Butoxamine & $100 \mu \mathrm{M}$ & $7.1 \pm 0.1$ & 4 & No response & & No response & 4 & No response & 4 \\
\hline Bupranolol & $10 \mu \mathrm{M}$ & $4.4 \pm 0.2$ & 4 & No response & 4 & No response & 4 & No response & 4 \\
\hline Timolol & $10 \mu \mathrm{M}$ & $5.0 \pm 0.3$ & 4 & $0.4 \pm 0.08$ & 3 & No response & 4 & No response & 4 \\
\hline Nadolol & $10 \mu \mathrm{M}$ & $2.6 \pm 0.3$ & 4 & No response & 4 & No response & 4 & No response & 4 \\
\hline Atenolol & $100 \mu \mathrm{M}$ & $2.1 \pm 1$ & 4 & No response & 4 & No response & 4 & No response & 4 \\
\hline Betaxolol & $100 \mu \mathrm{M}$ & $1.7 \pm 0.4$ & 4 & $0.5 \pm 0.1$ & 4 & No response & 4 & No response & 4 \\
\hline Nebivolol & $10 \mu \mathrm{M}$ & $1.2 \pm 0.3$ & 4 & No response & 4 & No response & 4 & No response & 4 \\
\hline Metoprolol & $100 \mu \mathrm{M}$ & No response & 4 & No response & 4 & No response & 4 & No response & 4 \\
\hline Sotalol & $100 \mu \mathrm{M}$ & No response & 4 & No response & 4 & No response & 4 & No response & 4 \\
\hline
\end{tabular}

Values are mean \pm SEM of $n$ separate determinations 

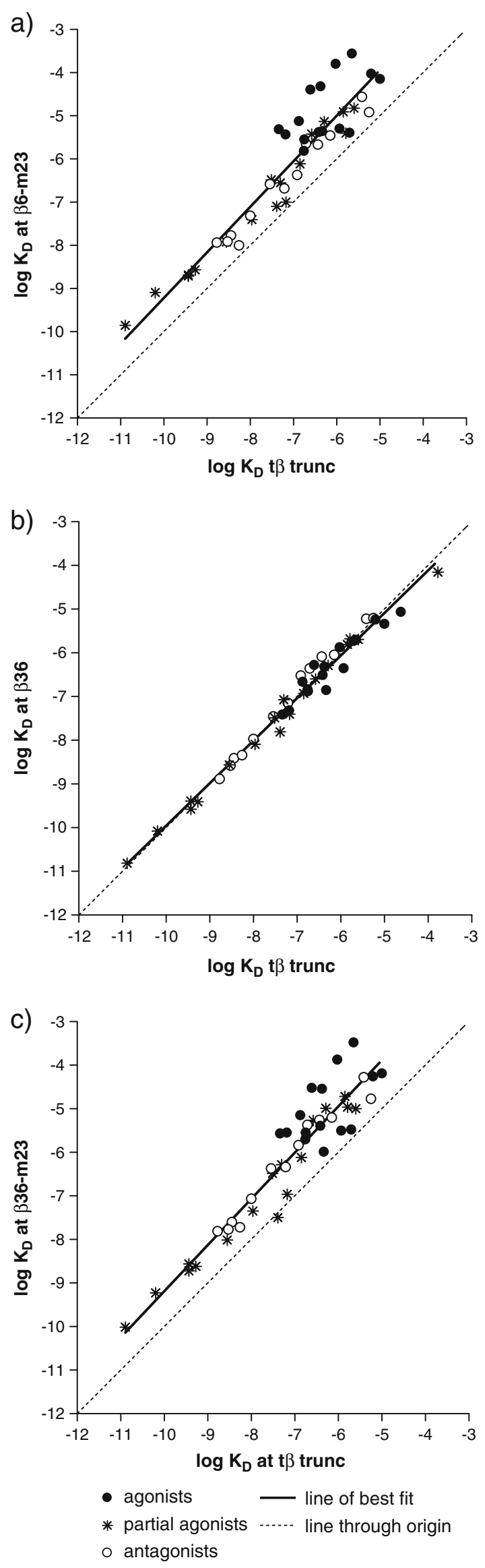

Fig. 3 Correlation plots of the $\log K_{D}$ values from ${ }^{3} \mathrm{H}-\mathrm{CGP} 12177$ whole cell binding for the turkey $\beta$-adrenoceptor mutants compared with each other. Ligands are shown as either full agonists (filled circles), partial agonists (asterisks) or antagonists (open circles). Categorisation into these classes was performed from data in Tables 2 and 3 , where ligands are defined as agonists if they stimulated more than $85 \%$ of the response at the human $\beta 1$-adrenoceptor, as partial agonists if they stimulated $10-85 \%$ of the full response and as antagonists if they stimulated less than $10 \%$ of a full agonist response at the $t \beta$ trunc receptor

determinations of total and nonspecific binding. In all cases where a $K_{D}$ value is stated, the competing ligand completely inhibited the specific binding of ${ }^{3} \mathrm{H}-\mathrm{CGP} 12177$.

A one-site sigmoidal response curve was then fitted to the data using Graphpad Prism 2.01 and the $\mathrm{IC}_{50}$ was then determined as the concentration required to inhibit $50 \%$ of the specific binding.

$\%$ of uninhibited binding $=100-\frac{(100 \times A)}{A+\mathrm{IC}_{50}}+\mathrm{NS}$

where, $A$ in the concentration of the competing ligand, $\mathrm{IC}_{50}$ is the concentration at which half of the specific binding of ${ }^{3} \mathrm{H}-\mathrm{CGP} 12177$ has been inhibited and NS is the nonspecific binding.

From the $\mathrm{IC}_{50}$ value and the known concentration of ${ }^{3} \mathrm{H}-\mathrm{CGP} 12177$, a $K_{D}$ value (concentration at which half the receptors are bound by the competing ligand) was calculated using the equation:

$K_{D}=\frac{I C_{50}}{1+\left(\left[{ }^{3} H-C G P 12177\right] / K_{D}{ }^{3} H-C G P 12177\right)}$

Functional assays $-{ }^{3} \mathrm{H}$-cAMP accumulation and CRE-SPAP production

Most agonist responses were best described by a one-site sigmoidal concentration response curve (Eq. 4)

Response $=\frac{E_{\mathrm{MAX}} \times[A]}{\mathrm{EC}_{50}+[A]}$

Where $E_{\mathrm{MAX}}$ is the maximum response, $[A]$ is the agonist concentration and $\mathrm{EC}_{50}$ is the concentration of agonist that produces $50 \%$ of the maximal response

The affinity of antagonists was calculated ( $K_{D}$ values) from the shift of the agonist concentration responses in the presence of a fixed concentration of antagonist using Eq. 5:

$\mathrm{DR}=1+\frac{[B]}{K_{D}}$

where, dose ratio (DR) is the ratio of the agonist concentration required to stimulate an identical response 

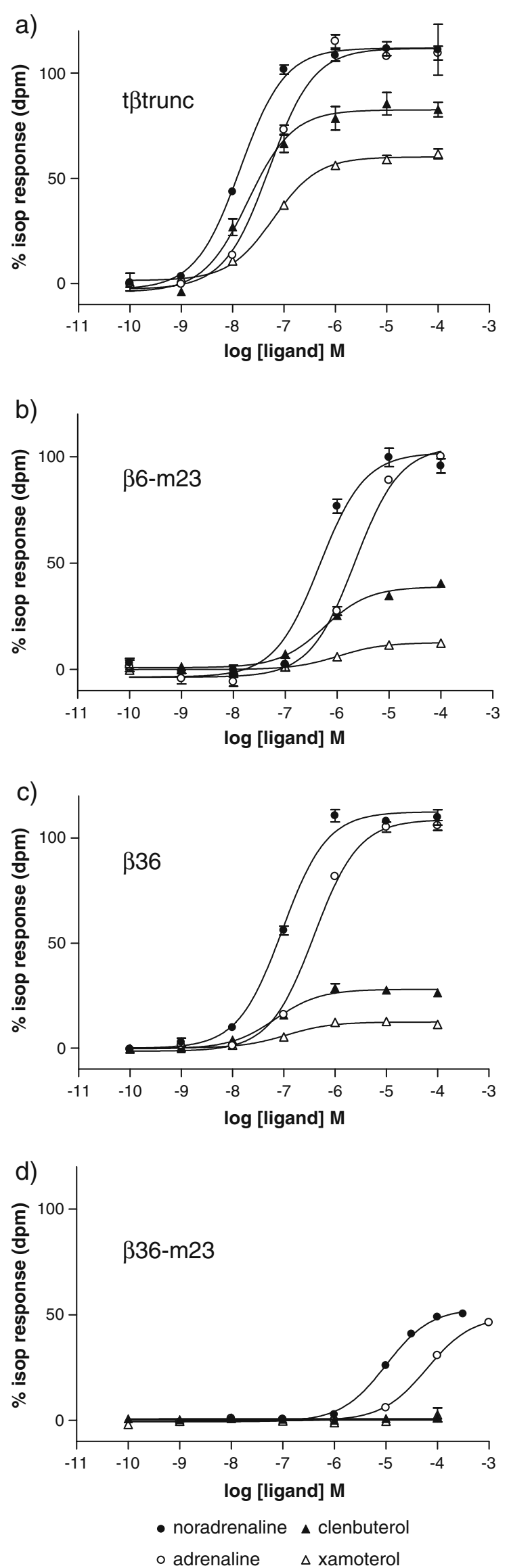

Fig. $4{ }^{3} \mathrm{H}$-cAMP accumulation in response to noradrenaline, adrenaline, clenbuterol and xamoterol in a t $\beta$ trunc cells, $\mathbf{b} \beta 6-\mathrm{m} 23$ cells, $\mathbf{c}$ $\beta 36$ cells and $\mathbf{d} \beta 36-\mathrm{m} 23$ cells expressed as a percentage of the maximal response to isoprenaline in each experiment. Data points are mean \pm SE mean of triplicate determinations. Each experiment is representative of a four, $\mathbf{b}$ four, $\mathbf{c}$ four and $\mathbf{d}$ three separate experiments

in the presence and absence of a fixed concentration of antagonist $[B]$.

In experiments where three different fixed concentrations of the same antagonist were used, Schild plots were constructed using the following Eq. 6:

$\log (\mathrm{DR}-1)=\log [B]-\log \left(K_{D}\right)$

These points were then fitted to a straight line. A slope of 1 then indicates competitive antagonism (Arunlakshana and Schild 1959).

When CGP 12177 was used to antagonise the more efficacious agonists where clear partial agonism was seen, the affinity was calculated by the method of Stephenson (1956) using Eq. 7:

$K_{D}$ partial agonist $=\frac{Y \times[P]}{1-Y}$ where $Y=\frac{\left[A_{2}\right]-\left[A_{1}\right]}{A_{3}}$

where $[P]$ in the concentration of CGP $12177,\left[A_{1}\right]$ in the concentration of the agonist at the point where CGP12177 alone causes the same response, $\left[A_{2}\right]$ is the concentration of agonist causing a given response above that achieved by CGP12177 and $\left[A_{3}\right]$ the concentration of the agonist, in the presence CGP12177, causing the same stimulation as $\left[A_{2}\right]$.

Several of the responses were however best fitted to a two-site concentration response-Eq. 8 (e.g. Fig. 9).

$$
\begin{aligned}
\% \text { maximal stimulation }= & \frac{[A] \times N}{\left([A]+\mathrm{EC} 1_{50}\right)} \\
& +\frac{[A] \times(100-N)}{\left([A]+\mathrm{EC} 2_{50}\right)}
\end{aligned}
$$

where $N$ is the percentage of site $1,[A]$ is the concentration of agonist and $\mathrm{EC}_{50}$ and $\mathrm{EC}_{50}$ are the respective $\mathrm{EC}_{50}$ values for the two agonist sites.

A two-site analysis was also used for experiments, e.g. Fig. 10 using Eq. 9:

$$
\begin{aligned}
\text { Response }= & \text { Basal }+(\mathrm{Ag}-\text { Basal }) \\
& \times\left(1-\frac{[P]}{\left([P]+\mathrm{IC}_{50}\right)}\right) \\
& +\mathrm{PAg}\left(\frac{[P]}{\left([P]+\mathrm{EC}_{50}\right)}\right)
\end{aligned}
$$


Table 4 Log $\mathrm{EC}_{50}$ values and \% isoprenaline maximal responses obtained from CRE-SPAP production in CHO t $\beta$ trunc cells

\begin{tabular}{|c|c|c|c|c|c|c|c|c|c|c|c|}
\hline $\mathrm{t} \beta \operatorname{trunc}^{\mathrm{a}}$ & $\log \mathrm{EC}_{50}$ & $\begin{array}{l}\% \text { isop } \\
\max \end{array}$ & $n$ & $\begin{array}{l}\log K_{D} \\
\text { propranolol }\end{array}$ & $n$ & $\begin{array}{l}\log K_{D} \\
\text { CGP20712A }\end{array}$ & & $\begin{array}{l}\log K_{D} \\
\text { ICI118551 }\end{array}$ & $n$ & $\begin{array}{l}\log K_{D} \\
\text { CGP12177 }\end{array}$ & $n$ \\
\hline Fenoterol & $-8.17 \pm 0.02$ & $120 \pm 5$ & 3 & $-8.84 \pm 0.05$ & 9 & $-8.20 \pm 0.00$ & 4 & $-7.43 \pm 0.05$ & 5 & $-9.66 \pm 0.09$ & 9 \\
\hline Formoterol & $-8.96 \pm 0.04$ & $115 \pm 5$ & 5 & $-8.77 \pm 0.03$ & 10 & $-8.20 \pm 0.10$ & 5 & $-7.44 \pm 0.09$ & 6 & $-9.65 \pm 0.07$ & 8 \\
\hline BRL37344 & $-6.45 \pm 0.05$ & $108 \pm 4$ & 8 & $-8.72 \pm 0.05$ & 6 & $-8.04 \pm 0.07$ & 75 & $-7.25 \pm 0.08$ & 8 & $-9.44 \pm 0.11$ & 11 \\
\hline Cimaterol & $-8.63 \pm 0.05$ & $122 \pm 5$ & 7 & $-8.70 \pm 0.05$ & 9 & $-8.24 \pm 0.09$ & 5 & $-7.49 \pm 0.04$ & 6 & $-9.54 \pm 0.07$ & 14 \\
\hline Clenbuterol & $-7.66 \pm 0.05$ & $102 \pm 4$ & 12 & $-8.52 \pm 0.05$ & 16 & $-7.82 \pm 0.09$ & 13 & $-7.32 \pm 0.10$ & 12 & $-9.40 \pm 0.07$ & 15 \\
\hline Salmeterol & $-6.86 \pm 0.05$ & $112 \pm 3$ & 13 & $-8.42 \pm 0.08$ & 10 & $-7.71 \pm 0.08$ & 11 & $-7.15 \pm 0.10$ & 9 & $-9.32 \pm 0.10$ & 9 \\
\hline Salbutamol & $-6.33 \pm 0.07$ & $105 \pm 4$ & 10 & $-8.41 \pm 0.10$ & 10 & $-7.93 \pm 0.09$ & 6 & $-7.19 \pm 0.08$ & 6 & $-9.34 \pm 0.11$ & 10 \\
\hline Adrenaline & $-7.13 \pm 0.08$ & $117 \pm 3$ & 8 & $-8.38 \pm 0.12$ & 13 & $-7.35 \pm 0.12$ & 9 & $-6.82 \pm 0.05$ & 7 & $-9.19 \pm 0.06$ & 8 \\
\hline Noradrenaline & $-7.74 \pm 0.04$ & $113 \pm 4$ & 12 & $-8.35 \pm 0.07$ & 16 & $-7.51 \pm 0.08$ & 11 & $-6.98 \pm 0.07$ & 13 & $-9.05 \pm 0.10$ & 11 \\
\hline Isoprenaline & $-8.11 \pm 0.12$ & 100 & 10 & $-8.21 \pm 0.10$ & 18 & $-7.25 \pm 0.13$ & 8 & $-6.72 \pm 0.12$ & 10 & $-9.19 \pm 0.11$ & 12 \\
\hline Dobutamine & $-6.53 \pm 0.06$ & $124 \pm 5$ & 3 & $-8.19 \pm 0.11$ & 9 & $-7.53 \pm 0.09$ & 5 & $-6.80 \pm 0.09$ & 4 & $-8.94 \pm 0.08$ & 7 \\
\hline CGP12177 & $-8.38 \pm 0.08$ & $53 \pm 4$ & 20 & $-7.23 \pm 0.12$ & 18 & $-6.91 \pm 0.15$ & 12 & $-6.36 \pm 0.17$ & 11 & & \\
\hline
\end{tabular}

$\log K_{D}$ values for propranolol, CGP20712, ICI118551 and CGP12177 as antagonists of the agonist responses are also given. Values are mean \pm SEM of $n$ separate determinations

${ }^{a}$ Data table from Baker 2010a

where basal is the response in the absence of agonist, $\mathrm{Ag}$ is the response to a fixed concentration of agonist, $[P]$ is the concentration of CGP12177, $\mathrm{IC}_{50}$ is the concentration of CGP 12177 that inhibits $50 \%$ of the response of the fixed agonist, PAg is the maximum stimulation by the CGP12177 and $\mathrm{EC}_{50}$ is the concentration of competing agonist that stimulated a half maximal CGP12177 response.

A $10 \mu \mathrm{M}$ (maximal) isoprenaline concentration was included in two to three wells in each plate for each separate experiment for ${ }^{3} \mathrm{H}-\mathrm{cAMP}$ accumulation and six wells of each plate for CRE-SPAP production and, to allow agonist responses to be expressed as a percentage of the isoprenaline maximum for each experiment. All data are presented as mean \pm SEM of triplicate determinations (except saturation binding experiments where determinations were from quadruplicate wells) and $n$ in the text refers to the number of separate experiments.

\section{Results}

Ligand affinity $-{ }^{3} \mathrm{H}-\mathrm{CGP} 12177$ whole cell binding

Binding studies were performed on both transiently transfected cells and the stable cell lines to ensure that the stable cell lines were indeed a true reflection of the pharmacology of the transfected receptors and that no alteration of the

Table 5 Log $\mathrm{EC}_{50}$ values and \% isoprenaline maximal responses obtained from CRE-SPAP production in CHO $\beta 6-\mathrm{m} 23$ cells

\begin{tabular}{|c|c|c|c|c|c|c|c|c|c|c|c|}
\hline$\beta 6-\mathrm{m} 23$ & $\log \mathrm{EC}_{50}$ & $\begin{array}{l}\% \text { isop } \\
\max \end{array}$ & $n$ & $\begin{array}{l}\log K_{D} \\
\text { propranolol }\end{array}$ & $n$ & $\begin{array}{l}\log K_{D} \\
\text { CGP20712A }\end{array}$ & & $\begin{array}{l}\log K_{D} \\
\text { ICI118551 }\end{array}$ & $n$ & $\begin{array}{l}\log K_{D} \\
\text { CGP12177 }\end{array}$ & $n$ \\
\hline Fenoterol & $-6.10 \pm 0.06$ & $92 \pm 2$ & 12 & $-8.33 \pm 0.06$ & 9 & $-7.25 \pm 0.06$ & 9 & $-7.03 \pm 0.04$ & 3 & $-9.32 \pm 0.07$ & 4 \\
\hline Formoterol & $-7.69 \pm 0.08$ & $107 \pm 2$ & 18 & $-8.24 \pm 0.02$ & 13 & $-7.19 \pm 0.07$ & 10 & $-6.97 \pm 0.04$ & 4 & $-9.03 \pm 0.11$ & 8 \\
\hline BRL37344 & $-5.37 \pm 0.07$ & $84 \pm 2$ & 12 & $-8.43 \pm 0.06$ & 7 & $-7.30 \pm 0.05$ & 6 & $-7.14 \pm 0.07$ & 3 & $-9.18 \pm 0.07$ & 3 \\
\hline Cimaterol & $-7.25 \pm 0.15$ & $96 \pm 2$ & 21 & $-8.29 \pm 0.04$ & 13 & $-7.34 \pm 0.07$ & 7 & $-6.99 \pm 0.03$ & 4 & $-9.13 \pm 0.05$ & 11 \\
\hline Clenbuterol & $-6.69 \pm 0.04$ & $77 \pm 3$ & 19 & $-8.14 \pm 0.08$ & 11 & $-7.28 \pm 0.14$ & 8 & $-7.10 \pm 0.04$ & 3 & $-8.88 \pm 0.07$ & 7 \\
\hline Adrenaline & $-5.81 \pm 0.08$ & $97 \pm 2$ & 14 & $-8.03 \pm 0.04$ & 14 & $-7.11 \pm 0.08$ & 3 & $-6.76 \pm 0.08$ & 5 & $-8.71 \pm 0.09$ & 7 \\
\hline Noradrenaline & $-6.27 \pm 0.10$ & $98 \pm 3$ & 15 & $-7.72 \pm 0.05$ & 14 & $-6.87 \pm 0.08$ & 5 & $-6.54 \pm 0.09$ & 5 & $-8.61 \pm 0.13$ & 7 \\
\hline Isoprenaline & $-7.39 \pm 0.11$ & 100 & 21 & $-7.63 \pm 0.10$ & 13 & $-6.74 \pm 0.13$ & 7 & $-6.55 \pm 0.14$ & 4 & $-8.84 \pm 0.22$ & 5 \\
\hline Dobutamine & $-5.90 \pm 0.06$ & $55 \pm 6$ & 10 & $-7.94 \pm 0.06$ & 4 & $-6.62 \pm 0.11$ & 1 & $-6.71 \pm 0.04$ & 4 & & \\
\hline CGP12177 & $-6.81 \pm 0.06$ & $20 \pm 2$ & 15 & $-6.03 \pm 0.11$ & 6 & $-6.42 \pm 0.20$ & 4 & $-5.39 \pm 0.16$ & 6 & & \\
\hline
\end{tabular}

$\log K_{D}$ values for propranolol, CGP20712, ICI118551 and CGP12177 as antagonists of the agonist responses are also given. Values are mean \pm SEM of $n$ separate determinations 
Table 6 Log $\mathrm{EC}_{50}$ values and \% isoprenaline maximal responses obtained from CRE-SPAP production in CHO $\beta 36$ cells

\begin{tabular}{|c|c|c|c|c|c|c|c|c|c|c|c|}
\hline$\beta 36$ & $\log \mathrm{EC}_{50}$ & $\begin{array}{l}\% \text { isop } \\
\max \end{array}$ & $n$ & $\begin{array}{l}\log K_{D} \\
\text { propranolol }\end{array}$ & $n$ & $\begin{array}{l}\log K_{D} \\
\text { CGP20712A }\end{array}$ & & $\begin{array}{l}\log K_{D} \\
\text { ICI118551 }\end{array}$ & $n$ & $\begin{array}{l}\log K_{D} \\
\text { CGP12177 }\end{array}$ & $n$ \\
\hline Fenoterol & $-7.88 \pm 0.03$ & $91 \pm 5$ & 3 & $-8.69 \pm 0.04$ & 9 & $-7.72 \pm 0.16$ & 4 & $-7.45 \pm 0.07$ & 5 & $-9.27 \pm 0.07$ & 9 \\
\hline Formoterol & $-8.66 \pm 0.06$ & $90 \pm 3$ & 4 & $-8.54 \pm 0.05$ & 10 & $-8.10 \pm 0.06$ & 5 & $-7.38 \pm 0.12$ & 6 & $-9.20 \pm 0.04$ & 9 \\
\hline BRL37344 & $-6.21 \pm 0.02$ & $90 \pm 5$ & 3 & $-8.74 \pm 0.04$ & 6 & $-8.03 \pm 0.09$ & 3 & $-7.41 \pm 0.05$ & 4 & $-9.35 \pm 0.06$ & 8 \\
\hline Cimaterol & $-8.51 \pm 0.02$ & $87 \pm 3$ & 6 & $-8.71 \pm 0.03$ & 10 & $-7.90 \pm 0.09$ & 5 & $-7.29 \pm 0.04$ & 6 & $-9.24 \pm 0.05$ & 13 \\
\hline Clenbuterol & $-7.27 \pm 0.03$ & $72 \pm 3$ & 6 & $-8.48 \pm 0.03$ & 16 & $-7.72 \pm 0.07$ & 8 & $-7.22 \pm 0.07$ & 7 & $-8.96 \pm 0.08$ & 10 \\
\hline Adrenaline & $-6.72 \pm 0.08$ & $95 \pm 3$ & 6 & $-7.99 \pm 0.10$ & 13 & $-6.89 \pm 0.17$ & 7 & $-6.77 \pm 0.09$ & 8 & $-8.97 \pm 0.09$ & 10 \\
\hline Noradrenaline & $-7.43 \pm 0.05$ & $102 \pm 4$ & 7 & $-8.00 \pm 0.05$ & 17 & $-7.25 \pm 0.09$ & 7 & $-6.89 \pm 0.09$ & 9 & $-8.83 \pm 0.07$ & 10 \\
\hline Isoprenaline & $-7.80 \pm 0.11$ & 100 & 6 & $-8.04 \pm 0.11$ & 14 & $-6.94 \pm 0.24$ & 7 & $-6.87 \pm 0.12$ & 8 & $-8.73 \pm 0.15$ & 9 \\
\hline Dobutamine & $-6.35 \pm 0.02$ & $102 \pm 3$ & 3 & $-8.21 \pm 0.06$ & 9 & $-7.33 \pm 0.05$ & 5 & $-6.88 \pm 0.06$ & 4 & $-8.69 \pm 0.07$ & 7 \\
\hline CGP12177 & $-7.74 \pm 0.11$ & $15 \pm 1$ & 10 & $-6.95 \pm 0.12$ & 12 & $-6.23 \pm 0.12$ & 8 & $-6.32 \pm 0.17$ & 8 & & \\
\hline
\end{tabular}

$\log K_{D}$ values for propranolol, CGP20712, ICI118551 and CGP12177 as antagonists of the agonist responses are also given. Values are mean \pm SEM of $n$ separate determinations

receptor pharmacology had taken place during the process of making the cell line. The results from eight separate transiently transfected cell populations (both $K_{D}$ of ${ }^{3} \mathrm{H}$ CGP12177 from saturation studies and $K_{D}$ values of betaxolol, bisoprolol, clenbuterol, CGP20712A, formoterol, ICI118551, metoprolol and xamoterol from competition studies) showed a similar pattern of $\log K_{D}$ values to those obtained from the stable cell line (Baker et al. 2008), so only the stable cell line data are presented here.

${ }^{3} \mathrm{H}-\mathrm{CGP} 12177$ bound specifically to all four turkey $\beta$ adrenoceptors mutants to give $K_{D}$ values (from all 96-, 48and 24-well plate methods combined) of $0.32 \pm 0.02 \mathrm{nM}(n=$ 28 ) for the $t \beta$ trunc (receptor expression level of $148 \mathrm{fmol} / \mathrm{mg}$ protein; Baker 2010a), $0.85 \pm 0.09 \mathrm{nM}(n=27)$ for the $\beta 6-$ $\mathrm{m} 23(2,785 \mathrm{fmol} / \mathrm{mg}$ protein), $0.34 \pm 0.02 \mathrm{nM}(n=26)$ for the $\beta 36(134 \mathrm{fmol} / \mathrm{mg}$ protein) and $0.88 \pm 0.08 \mathrm{nM}(n=28)$ for the $\beta 36-\mathrm{m} 23$ ( $254 \mathrm{fmol} / \mathrm{mg}$ protein) in the stable cell lines generated. The value presented in Baker (2010a) for the $\mathrm{t} \beta$ trunc receptor of $0.42 \mathrm{nM}$ is from the 96 -well plate method alone. The affinity of a range of other ligands (including agonists, partial agonists and neutral agonists, see below) was then assessed (Table 1, Fig. 2).

Agonist efficacy- ${ }^{3} \mathrm{H}$-cAMP accumulation and CRE-SPAP production

The agonist response to 24 ligands (seven-point concentration-response curves) was examined for each of the

Table 7 Log $\mathrm{EC}_{50}$ values and \% isoprenaline maximal responses obtained from CRE-SPAP production in CHO $\beta 36-\mathrm{m} 23$ cells

\begin{tabular}{|c|c|c|c|c|c|c|c|c|c|c|c|}
\hline$\beta 36-\mathrm{m} 23$ & $\log \mathrm{EC}_{50}$ & $\begin{array}{l}\% \text { isop } \\
\max \end{array}$ & $n$ & $\begin{array}{l}\log K_{D} \\
\text { propranolol }\end{array}$ & $n$ & $\begin{array}{l}\log K_{D} \\
\text { CGP20712A }\end{array}$ & & $\begin{array}{l}\log K_{D} \\
\text { ICI118551 }\end{array}$ & $n$ & $\begin{array}{l}\log K_{D} \\
\text { CGP12177 }\end{array}$ & $n$ \\
\hline Fenoterol & $100 \mu \mathrm{M}$ & $18 \pm 2$ & 5 & & & & & & & & \\
\hline Formoterol & $-5.97 \pm 0.05$ & $90 \pm 4$ & 4 & $-7.95 \pm 0.00$ & 3 & $-6.95 \pm 0.06$ & 4 & $-6.74 \pm 0.16$ & 4 & $-8.94 \pm 0.03$ & 4 \\
\hline BRL37344 & No response & & 3 & & & & & & & & \\
\hline Cimaterol & $10 \mu \mathrm{M}$ & $32 \pm 3$ & 8 & & & & & & & & \\
\hline Clenbuterol & No response & & 3 & & & & & & & & \\
\hline Adrenaline & $-4.67 \pm 0.03$ & $76 \pm 3$ & 6 & $-7.94 \pm 0.10$ & 10 & $-6.87 \pm 0.21$ & 3 & $-6.69 \pm 0.12$ & 4 & & \\
\hline Noradrenaline & $-5.20 \pm 0.04$ & $75 \pm 2$ & 9 & & & $-6.85 \pm 0.08$ & 9 & $-6.78 \pm 0.08$ & 9 & $-9.10 \pm 0.11$ & 6 \\
\hline Isoprenaline & $-6.20 \pm 0.02$ & 100 & 10 & $-8.02 \pm 0.04$ & 18 & $-6.66 \pm 0.04$ & 16 & $-6.64 \pm 0.03$ & 17 & $-9.05 \pm 0.03$ & 20 \\
\hline Dobutamine & No response & & 3 & & & & & & & & \\
\hline CGP12177 & No response & & 11 & & & & & & & & \\
\hline
\end{tabular}

$\log K_{D}$ values for propranolol, CGP20712, ICI118551 and CGP12177 as antagonists of the agonist responses are also given. Values are mean \pm SEM of $n$ separate determinations. For fenoterol and cimaterol, the response at the maximum concentration of 100 and $10 \mu \mathrm{M}$ respectively is given as the top of the concentration response curve at these concentrations had not been reached 
Table 8 Log $\mathrm{EC}_{50}$ values and \% isoprenaline maximal responses obtained from CRE-SPAP production in $\mathrm{CHO} \mathrm{t} \beta$ trunc, $\beta 6-\mathrm{m} 23, \beta 36$ and $\beta 36-\mathrm{m} 23$ ce01ls

\begin{tabular}{|c|c|c|c|c|c|c|c|c|c|c|c|c|}
\hline & $\begin{array}{l}\mathrm{t} \beta \text { trunc } \\
\log \mathrm{EC}_{50}\end{array}$ & $\%$ isop $\max$ & $n$ & $\begin{array}{l}\beta 6-\mathrm{m} 23 \\
\log \mathrm{EC}_{50}\end{array}$ & $\%$ isop max & $n$ & $\begin{array}{l}\beta 36 \\
\log \mathrm{EC}_{50}\end{array}$ & $\%$ isop $\max$ & $n$ & $\begin{array}{l}\beta 36-\mathrm{m} 23 \\
\log \mathrm{EC}_{50}\end{array}$ & $\%$ isop $\max$ & $n$ \\
\hline Salmeterol & $-6.86 \pm 0.05$ & $112 \pm 3$ & 13 & $-5.75 \pm 0.05$ & $61 \pm 4$ & 13 & $-6.57 \pm 0.02$ & $74 \pm 3$ & 8 & No response & 0 & 5 \\
\hline Terbutaline & $-6.09 \pm 0.08$ & $106 \pm 4$ & 3 & $-4.61 \pm 0.08$ & $61 \pm 8$ & 6 & $-5.89 \pm 0.03$ & $78 \pm 0.3$ & 3 & No response & 0 & 3 \\
\hline Salbutamol & $-6.33 \pm 0.07$ & $105 \pm 4$ & 10 & $-4.99 \pm 0.04$ & $50 \pm 2$ & 12 & $-5.89 \pm 0.04$ & $64 \pm 6$ & 3 & No response & 0 & 3 \\
\hline Tulobuterol & $-6.48 \pm 0.08$ & $77 \pm 10$ & 3 & $-5.13 \pm 0.04$ & $29 \pm 5$ & 7 & $-6.08 \pm 0.03$ & $58 \pm 3$ & 3 & No response & 0 & 3 \\
\hline ZD7114 & $-7.82 \pm 0.12$ & $63 \pm 3$ & 3 & $-7.15 \pm 0.04$ & $15 \pm 3$ & 3 & $-7.40 \pm 0.08$ & $56 \pm 5$ & 3 & No response & 0 & 3 \\
\hline Xamoterol & $-7.26 \pm 0.07$ & $68 \pm 1$ & 3 & $-5.77 \pm 0.12$ & $21 \pm 9$ & 3 & $-6.96 \pm 0.13$ & $51 \pm 5$ & 3 & No response & 0 & 3 \\
\hline Denopamine & $-6.70 \pm 0.07$ & $58 \pm 3$ & 5 & $10 \mu \mathrm{M}$ & $10 \pm 3$ & 4 & $-6.29 \pm 0.14$ & $40 \pm 2$ & 4 & No response & 0 & 3 \\
\hline Labetolol & $-7.58 \pm 0.19$ & $35 \pm 5$ & 3 & $-6.56 \pm 0.04$ & $13 \pm 2$ & 4 & $-7.48 \pm 0.03$ & $9.6 \pm 0.5$ & 3 & No response & 0 & 3 \\
\hline S-Cyanopindolol & $-10.22 \pm 0.16$ & $34 \pm 5$ & 7 & $-7.96 \pm 0.31$ & $16 \pm 3$ & 3 & $-9.62 \pm 0.09$ & $6.5 \pm 0.6$ & 3 & No response & 0 & 3 \\
\hline Pronethalol & $-7.23 \pm 0.16$ & $27 \pm 2$ & 3 & No response & 0 & 3 & No response & & & No response & 0 & 3 \\
\hline Carazolol & $-8.34 \pm 0.34$ & $25 \pm 3$ & 7 & No response & 0 & 3 & No response & & & No response & 0 & 3 \\
\hline
\end{tabular}

For denopamine in $36-\mathrm{m} 23$ cells, the response at the maximum concentration of $10 \mathrm{mM}$ is given as the top of the concentration response curve had not been reached by this maximum concentration. Values are mean \pm SEM of $n$ separate determinations

turkey $\beta$-adrenoceptor mutants (Table 2). A further 24 ligands were examined at maximum concentrations only (Table 3). This enabled ligands to be classified into full agonists (those ligands that stimulated a greater than $85 \%$ maximum response to isoprenaline in the cAMP assays at the $\mathrm{t} \beta$ trunc receptor), partial agonists (those that stimulated between $10-85 \%$ maximum responses at the $\mathrm{t} \beta$ trunc receptor) and antagonists (those ligands that stimulated less than $10 \%$ maximum response at the $\mathrm{t} \beta$ trunc receptor). This allowed the study of ligand affinity to be further examined to assess whether a particular subset of ligands (e.g. agonists) were disproportionately affected by the mutations (Fig. 3).

Initially, the ligands were incubated for $30 \mathrm{~min}$ with each cell line; however, as many responses were found to be very small, the response window was increased by extending the incubation time to $5 \mathrm{~h}$. This does not affect the position $\left(\mathrm{EC}_{50}\right.$ value) or maximum response of the concentration response curve in relation to isoprenaline or forskolin for the ligands, it merely increases the size of the response window enabling small responses to be observed more accurately (Baker 2010b). For example, the response to isoprenaline at $30 \mathrm{~min}$ and $5 \mathrm{~h}$ in each lines was, respectively: $\mathrm{t} \beta$ trunc, $-8.30 \pm 0.10(n=8)$ and $-8.54 \pm 0.13$ $(n=5) ; \beta 6-\mathrm{m} 23,-7.23 \pm 0.09(n=8)$ and $-7.22 \pm 0.11(n=5)$; $\beta 36,-7.48 \pm 0.14(n=8)$ and $-7.59 \pm 0.16(n=6)$; and $\beta 36-$ $\mathrm{m} 23,-5.84 \pm 0.02 \quad(n=8)$ and $-5.88 \pm 0.11 \quad(n=6)$. The numbers given in Table 2 are therefore a mean of all the 30-min and 5-h data.

Direct comparison of data between cell lines is not possible (even in these $\mathrm{CHO}$ cells) because levels of receptor expression vary and the coupling of receptors to effectors may also differ between the different cell lines.
Nevertheless, the rank order for the efficacy of ligands can be established by listing the ligands by the percentage of the maximum isoprenaline response observed. This was felt to be more appropriate than using Furchgott's efficacy ratio method (Furchgott 1966) as many of the ligands in this study stimulated partial agonist responses. Tables 2 and 3 are thus the response to agonist ligands presented in rank order of maximum response to isoprenaline as seen in the $t \beta$ trunc receptor cell line. Although there appear to be a few exceptions to the rank order using this method, they are generally in the ligands stimulating full agonist responses (e.g. dobutamine and ractopamine which have been shown to exhibit similar efficacy to BRL37344 and salbutamol at other $\beta$ adrenoceptors; Baker 2010b) and probably reflects the order in which the full agonists are presented. Generally, however the rank order of ligands, particularly once partial agonism is considered, is similar between $\mathrm{t} \beta$ trunc and the mutant receptors, with the $\mathrm{m} 23$ mutations and $\beta 36$ deletions causing a decrease in the amount of agonism seen and the $\beta 36-\mathrm{m} 23$ receptor being the most severely affected (Tables 2 and 3, Fig. 4).

As the cell lines were all constructed from the same parent cell line, assessing the response to forskolin (which directly stimulates adenylyl cyclase thereby being

Fig. 5 CRE-SPAP production in response to clenbuterol in the absence and presence of propranolol in a t $\beta$ trunc cells, b $\beta 6-\mathrm{m} 23$ cells, $\mathbf{c} \beta 36$ cells and d $\beta 36-\mathrm{m} 23$ cells. Bars represent basal CRE-SPAP production, that in response to $10 \mu \mathrm{M}$ isoprenaline and that in response 10,100 , 1,000 or $30,300,3,000 \mathrm{nM}$ propranolol alone. Data points are mean \pm SEM of triplicate determinations. The Schild slopes for each experiment are a 0.95 , b 0.98 and $\mathbf{c} 1.00$. Each experiment is representative of a five, $\mathbf{b}$ five, $\mathbf{c}$ five, and $\mathbf{d}$ three separate experiments 


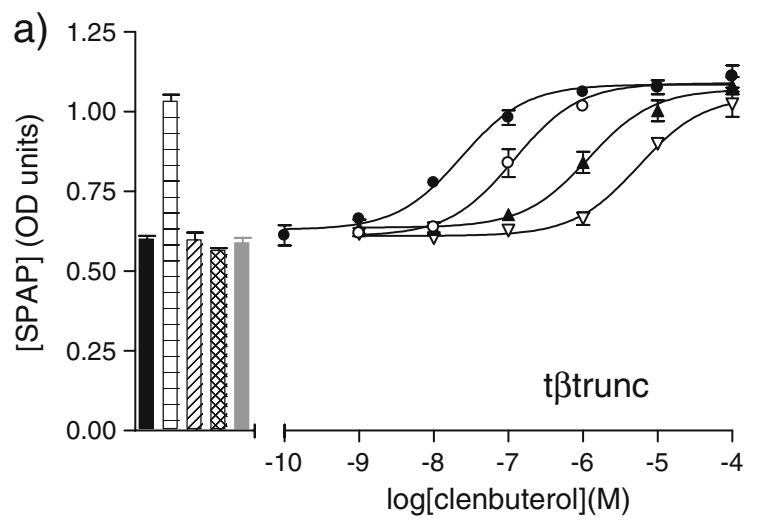

basal

日 isoprenaline $10 \mu \mathrm{M}$

propranolol 10nM

propranolol 100nM

propranolol 1000nM

- clenbuterol

- clenbuterol + propranolol 10nM

A clenbuterol + propranolol 100nM

$\nabla$ clenbuterol + propranolol 1000nM

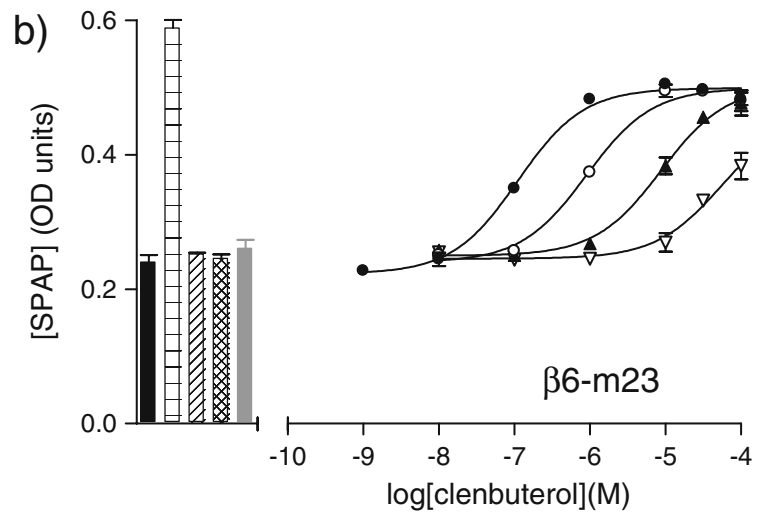

basal

$\mathrm{\theta}$ isoprenaline $10 \mu \mathrm{M}$

Q propranolol 30nM

propranolol 300nM

propranolol 3000nM

- clenbuterol

- clenbuterol + propranolol 30nM

A clenbuterol + propranolol 300nM

$\nabla$ clenbuterol + propranolol 3000nM

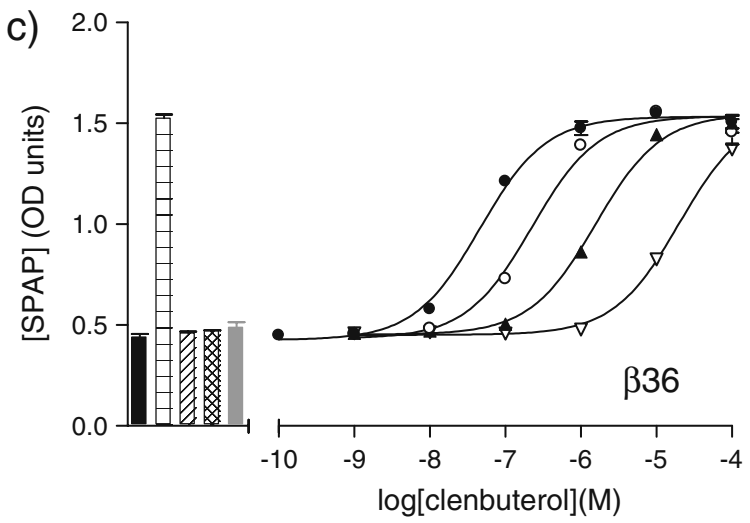

basal

$\mathrm{\theta}$ isoprenaline $10 \mu \mathrm{M}$

\& propranolol 10nM

propranolol 100nM

propanolol 1000nM

- clenbuterol

- clenbuterol + propranolol 10nM

\ clenbuterol + propranolol 100nM

$\nabla$ clenbuterol + propranolol 1000nM

d)

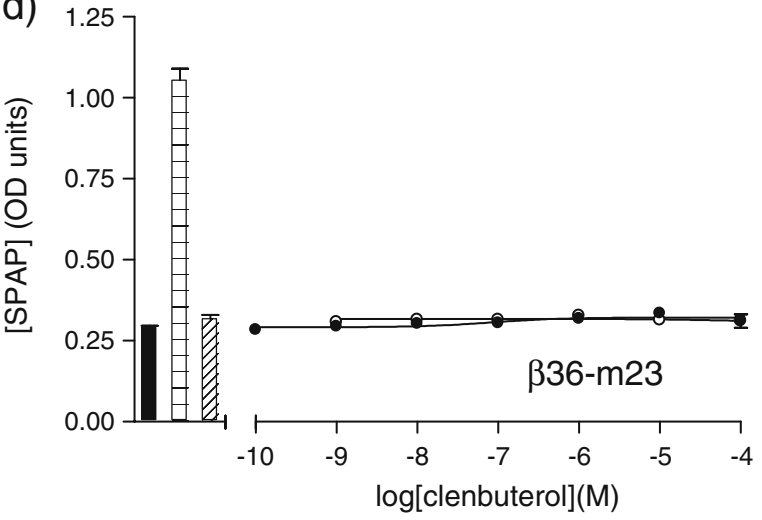

basal

$\theta$ isoprenaline $10 \mu \mathrm{M}$

\& propranolol 1000nM

- clenbuterol

- clenbuterol + propranolol 1000nM 
independent of the level of receptor expression and receptoreffector coupling and should therefore be constant in all lines) and comparing this to isoprenaline in each line might give information about receptor-effector coupling. For example, for equal receptor-effector coupling, a line with very high receptor expression would be expected to have a larger response (compared with forskolin) and left-shifted $\mathrm{EC}_{50}$ value for the agonist.

The response to $10 \mu \mathrm{M}$ forskolin was similar across all four cell lines (40.1 \pm 3 .9-fold over basal for $\mathrm{t} \beta$ trunc; $37.8 \pm$ 2.0 -fold over basal for $\beta 36 ; 37.6 \pm 2.2$-fold over basal for $\beta 6-\mathrm{m} 23$ and $40.7 \pm 3.9$-fold over basal for $\beta 36-\mathrm{m} 23$ cell line). Interestingly, the $\beta 6-\mathrm{m} 23$ cell line has a significantly higher receptor expression level than the other three cell lines and generated responses to isoprenaline that were far greater than the maximum response to forskolin (isoprenaline maximum was $197.8 \pm 10.5 \%$ of the forskolin response, $n=8$ ). The other cell lines generated lower total amounts of ${ }^{3} \mathrm{H}$-cAMP in response to isoprenaline relative to the forskolin response in each line, in keeping with their lower receptor expression levels ( $\mathrm{t} \beta$ trunc isoprenaline response was $35.9 \pm 4.5 \%$ forskolin, $n=5 ; \beta 36$ cell line isoprenaline response was $85.3 \pm 4.3 \%$ of forskolin, $n=6$; and the $\beta 36-\mathrm{m} 23$ cell line isoprenaline response was $107.4 \pm 14.6 \%$ of the forskolin response, $n=6$ ). Thus, despite having a lot more receptor available and being able to stimulate a maximum response far in excess of that in the $t \beta$ trunc line, the concentration of isoprenaline required to stimulate a response was significantly greater in the $\beta 6-\mathrm{m} 23$ cells than in the $\mathrm{t} \beta$ trunc cells $\left(\log \mathrm{EC}_{50}-8.40\right.$ in $\mathrm{t} \beta$ trunc cells vs. -7.23 in $\beta 6-\mathrm{m} 23$ cells). This suggests that the m23 mutations reduce the receptor's ability to generate a response either by reduced affinity, reduced ability to become activated or reduced receptor-effector coupling.

Isoprenaline stimulated CRE-SPAP gene transcription responses were 2.3- (Baker 2010a), 2.6 $\pm 0.01(n=21)-, 4.2 \pm$ $0.2(n=6)$ - and $2.7 \pm 0.10(n=10)$-fold over basal for $\mathrm{t} \beta$ trunc, $\beta 6-\mathrm{m} 23, \beta 36$ and $\beta 36-\mathrm{m} 23$ receptors respectively (Tables 4 , 5,6 and 7). Once again (better seen in Table 8 where partial agonists were examined), the $\mathrm{m} 23$ mutations and $\beta 36$ deletions generated lower agonist responses than the $t \beta$ trunc cell line and the $\beta 36-\mathrm{m} 23$ mutant was the most severely affected; however, the rank order of agonist efficacy remained largely undisturbed.
Fig. 6 CRE-SPAP production in response to cimaterol in a $\beta 6-\mathrm{m} 23$ and $\mathbf{b} \beta 36$ cells in the absence and presence of CGP12177. Bars represent basal CRE-SPAP production that in response to $10 \mu \mathrm{M}$ isoprenaline and that in response $1,10,30$ or $100 \mathrm{nM}$ CGP12177 alone. Data points are mean \pm SEM of triplicate determinations. Each experiment is representative of $\mathbf{a}$ five and $\mathbf{b}$ five separate experiments
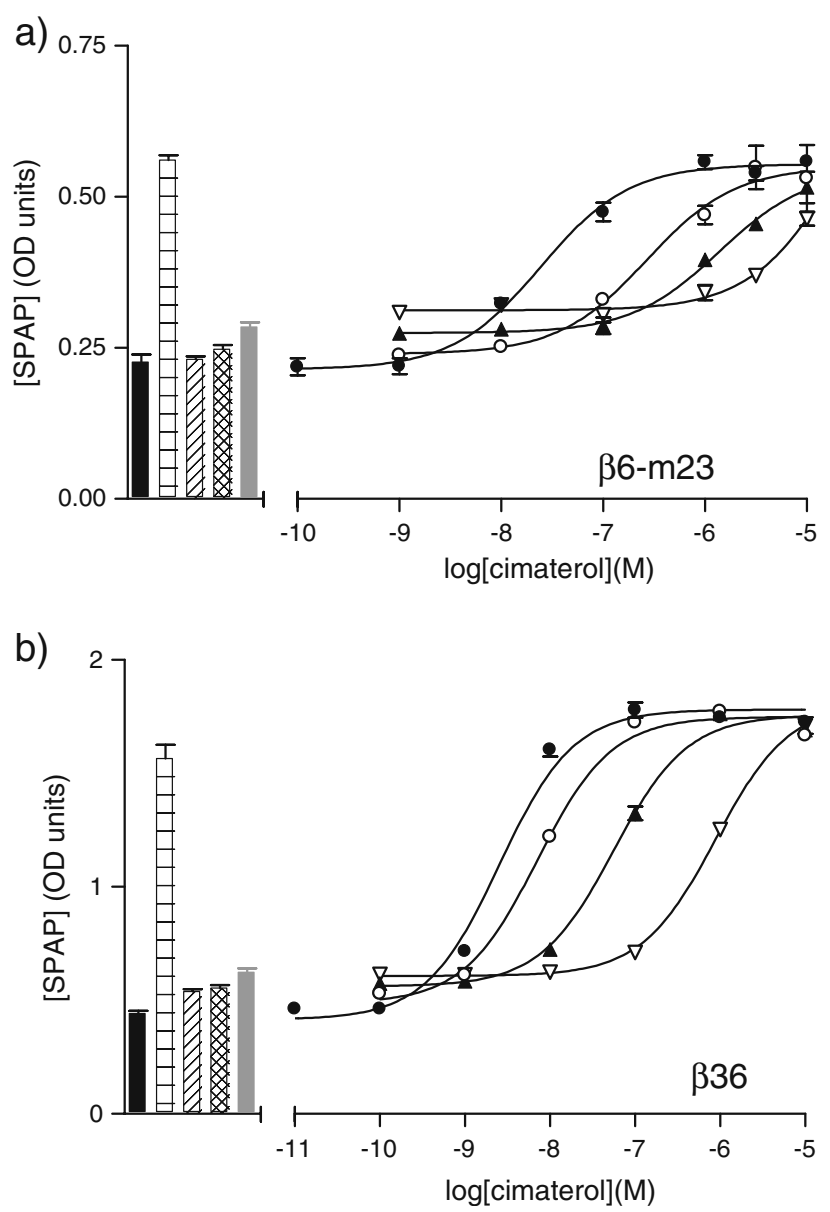

basal

日 isoprenaline $10 \mu \mathrm{M}$ CGP 12177 10nM CGP 12177 30nM CGP 12177 100nM

- cimaterol

- cimaterol + CGP 12177 10nM

- cimaterol + CGP 12177 30nM

$\nabla$ cimaterol + CGP 12177 100nM basal

$\theta$ isoprenaline $10 \mu \mathrm{M}$

๑ CGP $121771 \mathrm{nM}$

CGP 12177 10nM

CGP 12177 100nM

- cimaterol

- cimaterol + CGP 12177 1nM

- cimaterol + CGP 12177 10nM

$\nabla$ cimaterol + CGP 12177 100nM 
Evidence for two agonist-induced conformations - ${ }^{3} \mathrm{H}-\mathrm{cAMP}$ accumulation and CRE-SPAP production

Next, the $\beta 36$ deletions and the $\mathrm{m} 23$ mutations were each examined separately to determine the effects of these mutations on the two agonist-induced conformations of the $t \beta$ trunc receptor. Several agonists stimulated CRE-SPAP responses that were inhibited by propranolol, CGP20712A and ICI118551 (Fig. 5, Tables 4, 5, 6 and 7) in a competitive manner. CGP12177 also acted as an antagonist, inhibiting both of these mutant receptor responses with high affinity (Fig. 6, Tables 4, 5, 6 and 7). Also, CGP12177 itself stimulated a partial agonist response at both of these mutants and in each case the log $\mathrm{EC}_{50}$ value was significantly higher than the $K_{D}$ value for CGP12177 at the mutant receptor (Fig. 7, Tables 4, 5, 6 and 7). In addition, these CGP12177 agonist responses required significantly higher concentrations of propranolol, CGP20712A and ICI118551 to be inhibited than the other agonists (Fig. 7, Tables 4, 5, 6 and 7). This is in keeping with two agonist-induced conformations (a catecholamine site conformation and a secondary CGP12177 site conformation) on each of the $\beta 36$ and $\beta 6-\mathrm{m} 23$ receptor mutants.
When these mutations were combined in the $\beta 36-\mathrm{m} 23$ mutant receptor, many agonists did not stimulate any response (Fig. 5d, Tables 7 and 8). In addition, CGP12177 itself did not stimulate any agonist response at the $\beta 36-\mathrm{m} 23$ receptor making it difficult to determine whether this mutant does indeed have two agonist-induced conformations. However, responses were seen to a few agonists and these responses were inhibited by classical antagonists in a competitive manner (propranolol, ICI118551 and CGP20712A, Fig. 8a, Table 7). In addition, CGP12177 also inhibited these agonist responses with high affinity in a similar manner to the original $\mathrm{t} \beta$ trunc receptor (Fig. $8 \mathrm{~b}$, Table 7).

Further evidence for two sites or conformations was also sought by using the ${ }^{3} \mathrm{H}$-cAMP accumulation assay, which has the largest response window, thus making the detailed examination of agonist responses possible. SCyanopindolol was the ligand bound to the $\beta 36-\mathrm{m} 23$ receptor from which the X-ray structure was determined (Warne et al. 2008) and it stimulated an ${ }^{3} \mathrm{H}$-cAMP accumulation response that was best described by a twocomponent response curve (Fig. 9a). CGP12177 and carazolol similarly stimulated two-component response curves (Table 9). Two component response curves were also seen for $\beta 6-\mathrm{m} 23$ and $\beta 36$ receptors (Fig. 9b and c,
Fig. 7 CRE-SPAP production in response to CGP12177 in a $\beta 6-\mathrm{m} 23$ and $\mathbf{b} \beta 36$ cells in the absence and presence of propranolol. Bars represent basal CRE-SPAP production, that in response to $10 \mu \mathrm{M}$ isoprenaline and that in response 1,10 or $100 \mu \mathrm{M}$ propranolol alone. Data points are mean \pm SEM of triplicate determinations. Each experiment is representative of $\mathbf{a}$ five and $\mathbf{b}$ five separate experiments

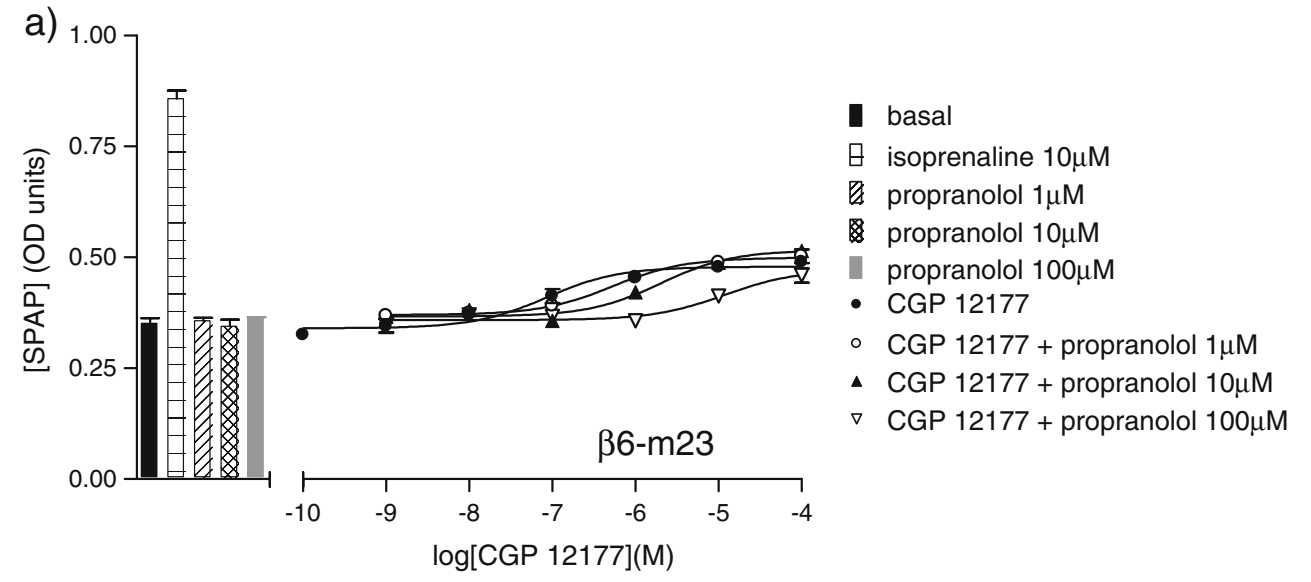

b)

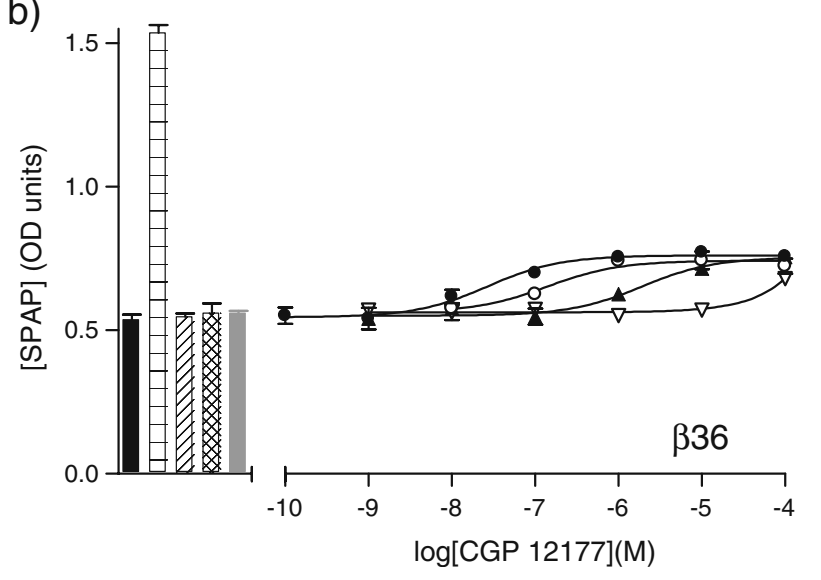

basal

$\theta$ isoprenaline $10 \mu \mathrm{M}$

\& propranolol $1 \mu \mathrm{M}$

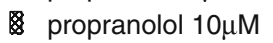

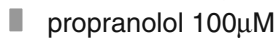

- CGP 12177

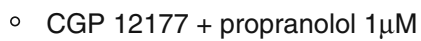

- CGP 12177 + propranolol 10 $\mu \mathrm{M}$

$\nabla$ CGP $12177+$ propranolol $100 \mu \mathrm{M}$ 
Fig. 8 CRE-SPAP production in response to isoprenaline in $\beta 36-\mathrm{m} 23$ cells in the absence and presence of a propranolol and b CGP12177. Bars represent basal CRE-SPAP production, that in response to $10 \mu \mathrm{M}$ isoprenaline and that in response $10,1001,000 \mathrm{nM}$ propranolol or 1,10 or $100 \mathrm{nM}$ CGP12177 alone. Data points are mean \pm SEM of triplicate determinations. Each experiment is representative of $\mathbf{a}$ seven and $\mathbf{b}$ seven separate experiments. The Schild slopes for each experiment are $\mathbf{a} 1.00$ and $\mathbf{b} 1.05$

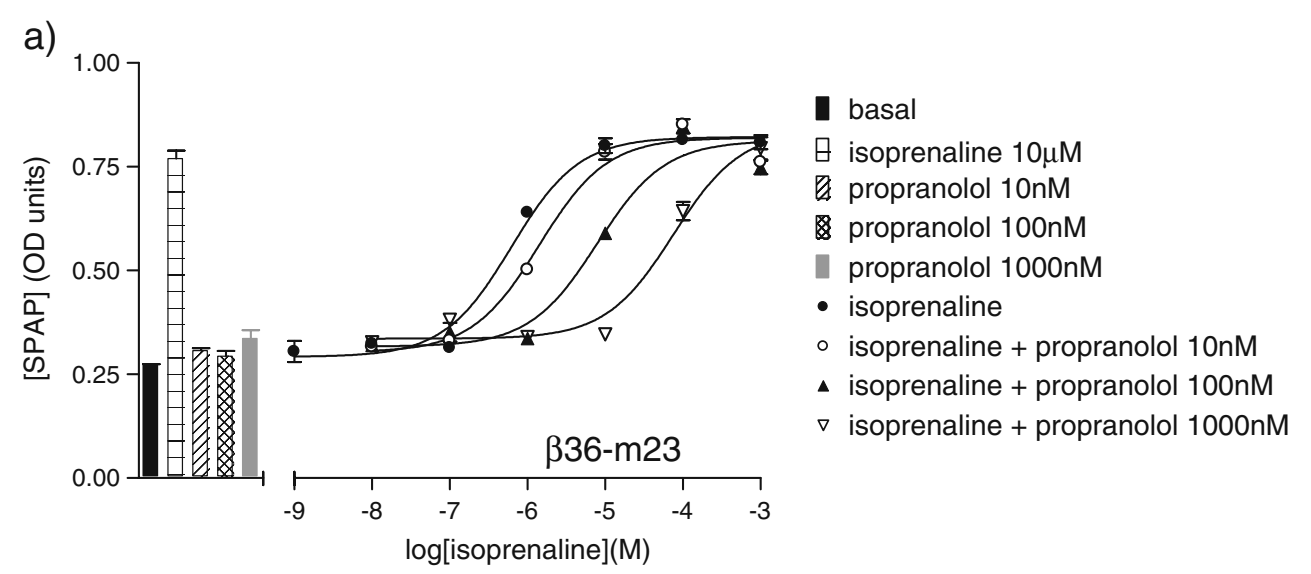

b)

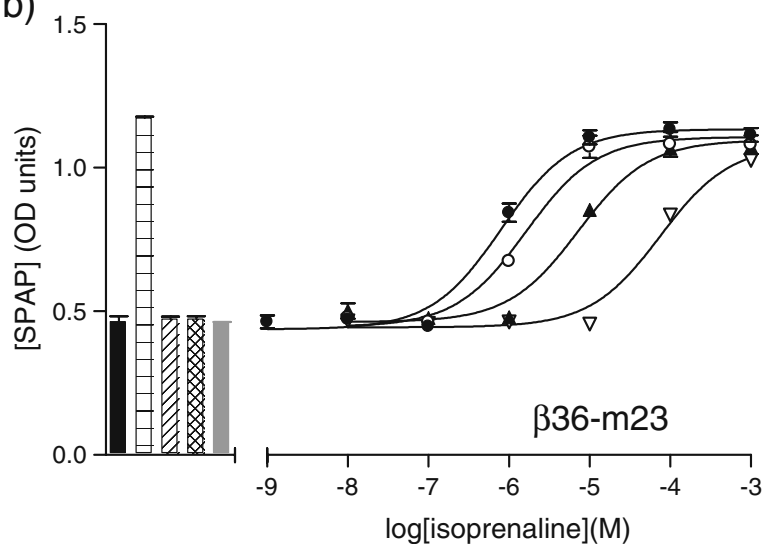

basal

$\boxminus$ isoprenaline $10 \mu \mathrm{M}$

Q CGP 12177 1nM

CGP 12177 10nM

CGP 12177 100nM

- isoprenaline

- isoprenaline + CGP 12177 1nM

$\Delta$ isoprenaline + CGP 12177 10nM

$\nabla$ isoprenaline + CGP 12177 100nM
Table 9). No responses to cyanopindolol, carazolol or CGP12177 were seen for the $\beta 36-\mathrm{m} 23$ receptor (Fig. 9d).

Finally, at the original $\mathrm{t} \beta$ trunc receptor, the stimulatory responses to cimaterol were inhibited by low concentrations of CGP12177, with higher concentrations of CGP12177 causing the CGP12177 agonist response (Fig. 10a). This pattern, which can only be explained by two agonist sites or conformations (Baker 2010a), was also seen at the $\beta 6-\mathrm{m} 23$ and $\beta 36$ mutant receptors (Fig. 10b, c). Similar patterns were also seen with isoprenaline, clenbuterol and formoterol as agonists. Only the inhibition of the agonist responses to isoprenaline, cimaterol and formoterol were seen at the $\beta 36-\mathrm{m} 23$ receptor (Fig. 10d).

\section{Parent CHO cells}

There was no specific binding of ${ }^{3} \mathrm{H}-\mathrm{CGP} 12177$ to the parent $\mathrm{CHO}$ cells (i.e. $\mathrm{CHO}$ cells without a transfected receptor). In addition, in the ${ }^{3} \mathrm{H}$-cAMP accumulation cAMP assay and the CRE-SPAP gene transcription assay, the parent $\mathrm{CHO}$ cells responded to forskolin but no responses were seen to any of the other ligands used in this study (Baker 2010a).

\section{Discussion}

Effect of the $\beta 36$ deletions and $\mathrm{m} 23$ mutations on ligand affinity

The X-ray crystal structure of the turkey $\beta$-adrenoceptor was recently determined but several mutations were required to stabilise the protein before the crystallisation process could occur (Warne et al. 2008, 2009). To realise the full potential of this structure, it is important to understand the extent to which these mutations affects the pharmacology. Firstly, ligand affinity was examined. The $\beta 36$ deletions made no difference to the ability of ligands to bind (compared to the $\mathrm{t} \beta$ trunc construct). This was true for agonists, partial agonists and neutral antagonists. In the correlation plot (Fig. 3b), the ligands are clearly seen to have the same affinity for both the $\mathrm{t} \beta$ trunc and $\beta 36$

Fig. $9{ }^{3} \mathrm{H}$-cAMP accumulation in response to cyanopindolol in a $\mathrm{t} \beta$ trunc cells, b $\beta 6-\mathrm{m} 23$ cells, $\mathbf{c} \beta 36$ cells and d $\beta 36-\mathrm{m} 23$ cells. Bars represent basal ${ }^{3} \mathrm{H}$-cAMP accumulation and that in response to $10 \mu \mathrm{M}$ isoprenaline. Data points are mean $\pm \mathrm{SE}$ mean of triplicate determinations. Each experiment is representative of a four, b 12, c six and $\mathbf{d}$ three separate experiments 

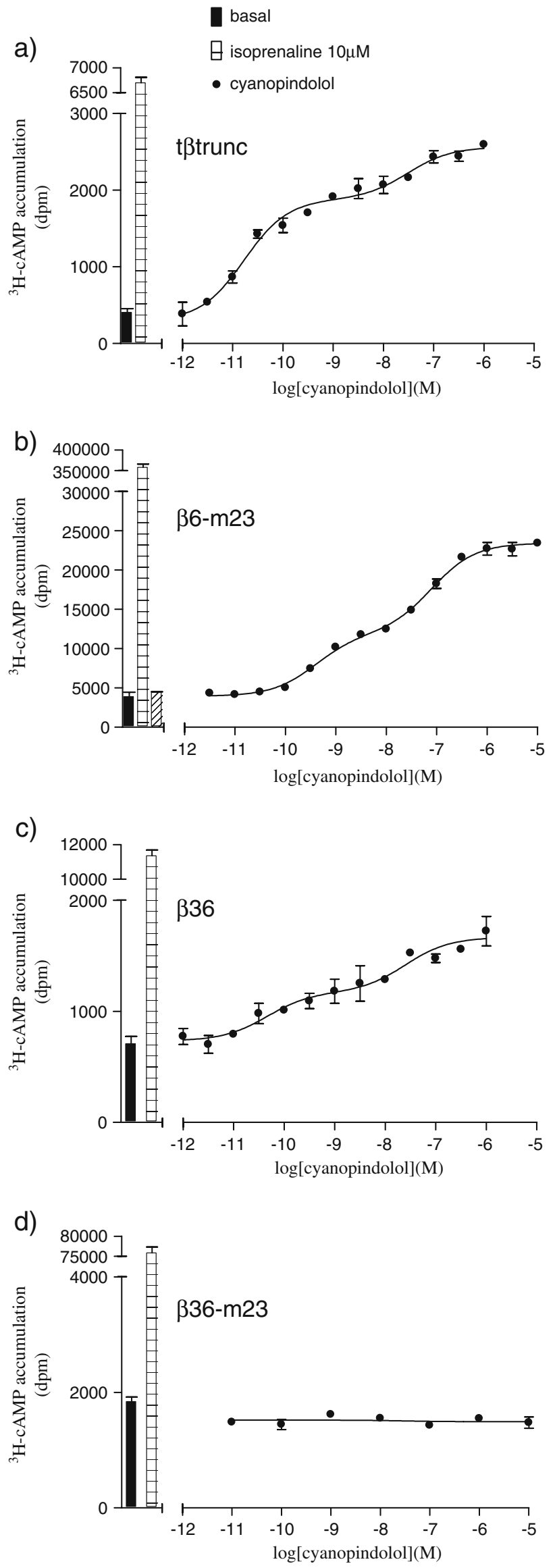

receptor and the line of best-fit passes through the origin. This is consistent with the view that the N-terminus, Cterminus and most of cytoplasmic loop 3 do not interact directly or indirectly with the ligand-binding pocket.

The m23-thermostabilising mutations resulted in a lower affinity for all ligands-agonists, partial agonists or neutral antagonists. The line of best fit (Fig. 3a, c) does not pass through the origin for either $\beta 6-\mathrm{m} 23$ or $\beta 36-\mathrm{m} 23$ receptors because all the ligands have about tenfold lower affinity. Interestingly, several of the most efficacious agonists (e.g. fenoterol, cimaterol, adrenaline, formoterol, noradrenaline and isoprenaline) have a greater than tenfold reduction in affinity with the $\mathrm{m} 23$ mutations, but this is not uniform across all agonists.

Previous ligand binding data for $\beta 6-\mathrm{m} 23$ (Serrano-Vega et al. 2008) showed that cyanopindolol and dihydroalprenolol bound to the thermostabilised receptor with similar affinities to the unmutated receptor, whereas the binding of the agonists isoprenaline and noradrenaline was weaker by 650- and 2,470-fold, respectively. The significant difference between these results and the results presented here is most likely related to the environment in which these assays were performed. The binding experiments of Serrano-Vega et al. (2008) were performed on Escherichia coli-expressed receptors after solubilisation in the detergent dodecylmaltoside, whereas the binding experiments performed here were in living mammalian whole cells.

Effect of the $\beta 36$ deletions and m23 mutations on ligand efficacy and receptor activation

Next, the effect on ligand efficacy (or ability for receptor activation) was investigated. As agonist efficacy depends on many factors, including the level of receptor expression (Clarke and Bond 1998; Kenakin 1999, 2002), it is difficult to directly compare across cell lines. However, in both functional assays, the catecholamines isoprenaline, adrenaline and noradrenaline were able to stimulate agonist response via all four receptors, including $\beta 36-\mathrm{m} 23$ although much higher concentrations of agonist were required to achieve this.

As ligand affinity is reduced in the $\beta 6-\mathrm{m} 23$ and $\beta 36-$ m23 mutants, all other things being equal, higher concentrations of agonist would be expected to be required to stimulate a response compared to the $t \beta$ trunc or $\beta 36$ mutant. This was indeed observed, even in the $\beta 6-\mathrm{m} 23$ line with its higher receptor expression level. Looking further at the other agonist ligands, with a range of efficacies from full to weak partial agonists (e.g. Tables 3 and 8), progressively fewer ligands were able to stimulate agonist responses via the $\beta 36$ and $\beta 6-\mathrm{m} 23$ mutants alone. For the $\beta 6-\mathrm{m} 23$ receptor, the reduced ability of the receptor to activate a response, whilst partly being 
Table 9 Log $\mathrm{EC}_{50}$ values and $\%$ isoprenaline maximal responses obtained in response to S-cyanopindolol, carazolol and CGP 12177 from ${ }^{3} \mathrm{H}-\mathrm{cAMP}$ accumulation responses in $\mathrm{CHO}$ $\mathrm{t} \beta$ trunc, $\beta 6-\mathrm{m} 23, \beta 36$ and $\beta 36-\mathrm{m} 23$ cells

Where the response is best described by a two-component response, the $\log \mathrm{EC}_{50} 1$ and $\log$ $\mathrm{EC}_{50} 2$ are given along with the $\%$ of the response occurring at site 1 . Values are mean \pm SEM of $n$ separate determinations

\begin{tabular}{lllllll}
\hline Ligand & receptor & $\log _{50} 1$ & $\log _{50} 2$ & $\%$ site 1 & $\%$ isoprenaline max & $n$ \\
\hline S-Cyanopindolol & $\mathrm{t} \beta$ trunc & $-10.72 \pm 0.06$ & $-7.84 \pm 0.13$ & $67 \pm 1$ & $39 \pm 1$ & 4 \\
& $\beta 6-\mathrm{m} 23$ & $-9.24 \pm 0.06$ & $-6.88 \pm 0.11$ & $44 \pm 2$ & $9.2 \pm 1.0$ & 12 \\
& $\beta 36$ & $-10.42 \pm 0.36$ & $-7.46 \pm 0.36$ & $66 \pm 5$ & $7.4 \pm 4.9$ & 6 \\
& $\beta 36-\mathrm{m} 23$ & No response & & & & 3 \\
Carazolol & $\mathrm{t} \beta$ trunc & $-9.96 \pm 0.06$ & $-6.70 \pm 0.08$ & $43 \pm 2$ & $21 \pm 1$ & 8 \\
& $\beta 6-\mathrm{m} 23$ & $-8.69 \pm 0.24$ & $-6.14 \pm 0.18$ & $25 \pm 3$ & $2.5 \pm 0.2$ & 8 \\
& $\beta 36$ & $-9.92 \pm 0.52$ & $-6.52 \pm 0.21$ & $43 \pm 10$ & $3.4 \pm 0.5$ & 5 \\
CGP 12177 & $\beta 36-\mathrm{m} 23$ & No response & & & & 3 \\
& $\mathrm{t} \beta$ trunc & $-9.18 \pm 0.03$ & $-6.73 \pm 0.17$ & $56 \pm 3$ & $51 \pm 3$ & 11 \\
& $\beta 6-\mathrm{m} 23$ & $-7.96 \pm 0.11$ & $-5.94 \pm 0.15$ & $35 \pm 2$ & $11 \pm 2$ & 6 \\
& $\beta 36$ & $-9.26 \pm 0.15$ & $-6.78 \pm 0.15$ & $54 \pm 5$ & $11 \pm 5$ & 9 \\
\hline
\end{tabular}

due to the reduction in affinity, is also consistent with the theory that the m23 mutations increase the stability of the receptor and thus increase the energy barrier required for receptor activation. However, as the $\beta 36$ deletions did not affect ligand affinity, the reduced ability of the $\beta 36$ mutant to activate responses may be a direct effect of the mutations reducing the receptor-G-protein interaction, consistent with extensive data implicating cytoplasmic loop 3 and the C-terminus of GPCRs in the receptor-G-protein activation process.

When the two were combined, the effect was even more striking with very few agonists being able to elicit a response from the $\beta 36-\mathrm{m} 23$ mutant.

The effect of the $\beta 36$ deletions and $\mathrm{m} 23$ mutations on the two agonist-induced conformations

The human $\beta_{1}$-adrenoceptor and the $\mathrm{t} \beta$ trunc exist in two pharmacologically active agonist-induced conformations, consisting of a high-affinity site where catecholamines stimulate responses and classical $\beta$-adrenoceptor antagonists bind with high affinity and a secondary site where CGP12177 stimulates an agonist response and classical antagonists have much higher affinity (Arch 2004; Baker 2005a, 2010a; Granneman 2001; Kaumann and Molenaar 2008; Konkar et al. 2000; Lowe et al. 2002; Molenaar 2003). Thus, CGP12177 binds to the $\mathrm{t} \beta$ trunc catecholamine site with high affinity $\left(K_{D} 0.32 \mathrm{nM}\right.$ from ${ }^{3} \mathrm{H}-$ CGP12177 binding and $0.22-1.5 \mathrm{nM}$ from antagonism of agonist responses; Baker 2010a), but requires higher concentrations to stimulate agonist responses $\left(\mathrm{EC}_{50}\right.$ $4.17 \mathrm{nM}$ ), suggesting that this CGP12177 agonist response is occurring via a secondary site (Baker 2010a). Furthermore, the concentrations of antagonists required to inhibit the CGP12177 response are significantly higher than those required to inhibit the other agonist responses (Baker 2010a).
In the $\beta 6-\mathrm{m} 23$ and $\beta 36$ mutants, CGP12177 bound with high affinity in both the binding assay and as an antagonist in the functional CRE-SPAP assay suggesting that CGP12177 binds with high affinity to the catecholamine site on both mutants. CGP12177 also stimulated agonist responses via both of these mutations but required a higher concentration (higher $\mathrm{EC}_{50}$ value) than expected from its $K_{D}$ value at each receptor $\left(\beta 6-\mathrm{m} 23 K_{D} 0.85 \mathrm{nM}\right.$ on binding, $K_{D} 0.48-1.45 \mathrm{nM}$ on CRE-SPAP but $\mathrm{EC}_{50}$ of $155 \mathrm{nM}$ on CRE-SPAP; $\beta 36 K_{D} 0.34 \mathrm{nM}$ on binding, $K_{D}$ 0.54-2.04 nM on CRE-SPAP but $\mathrm{EC}_{50}$ of $18.2 \mathrm{nM}$ on CRE-SPAP). Also, the concentration of antagonists required to inhibit the CGP12177 agonist responses were significantly higher than those required to inhibit the other agonists. This suggests that the $\beta 6-\mathrm{m} 23$ receptor and the $\beta 36$ receptor both exist in at least two agonist-induced conformations. When both mutations are combined $(\beta 36-$ m23), CGP12177 was able to bind with high affinity and antagonise catecholamine responses with high affinity, suggesting that CGP12177 binds with high affinity catecholamine site on the receptor. However, CGP12177 itself did not simulate an agonist response via the $\beta 36-\mathrm{m} 23$ receptor. This could be because either the ability of the $\beta 36-\mathrm{m} 23$ receptor to stimulate responses is too poor to allow detection of partial agonist responses or because the combination of the $\beta 36$ deletions and the m23 mutations has disrupted the secondary site on the turkey receptor.

Further evidence for two receptor conformations comes from ligands that stimulate two-component concentration response curves (Baker et al. 2003; Walter et al. 1984)examples at the $\mathrm{t} \beta$ trunc receptor being CGP12177 itself, Scyanopindolol and carazolol (Baker 2010a). CGP12177, carazolol and S-cyanopindolol all stimulated twocomponent agonist response curves via both the $\beta 6-\mathrm{m} 23$ and $\beta 36$ receptors. This again suggests that neither mutation cause a major disruption to the secondary site on the receptor. Once again, no response was seen in the 


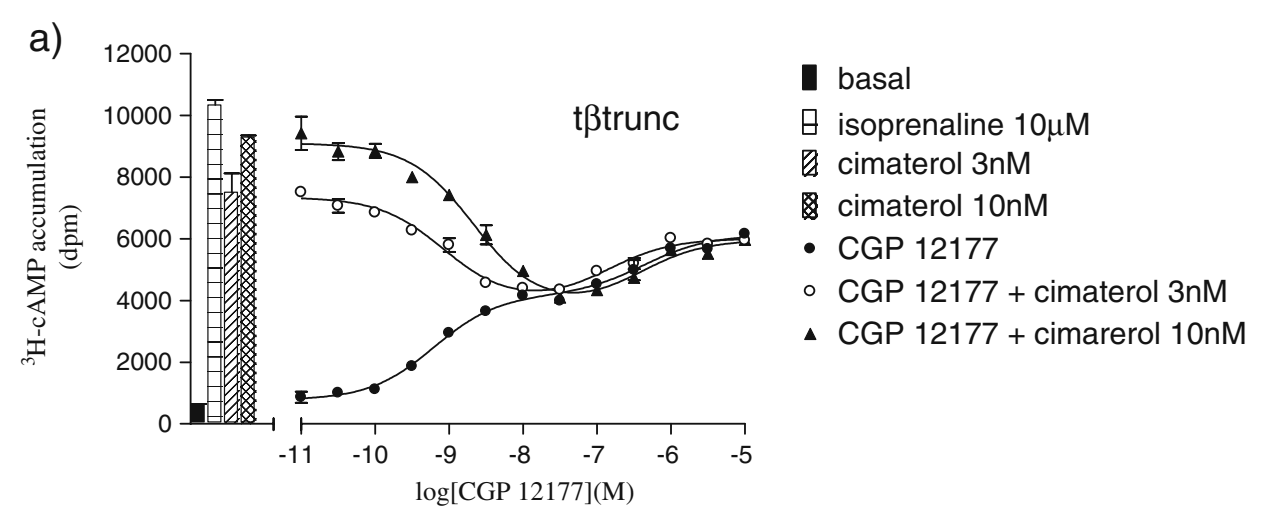

b)

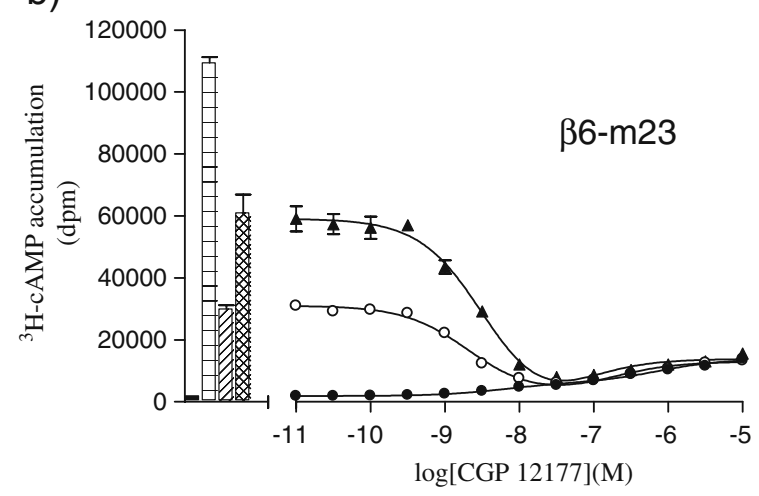

basal

$\mathrm{\theta}$ isoprenaline $10 \mu \mathrm{M}$

(2) cimaterol 30nM

cimaterol 100nM

- CGP 12177

- CGP 12177 + cimaterol 30nM

- CGP 12177 + cimaterol 100nM

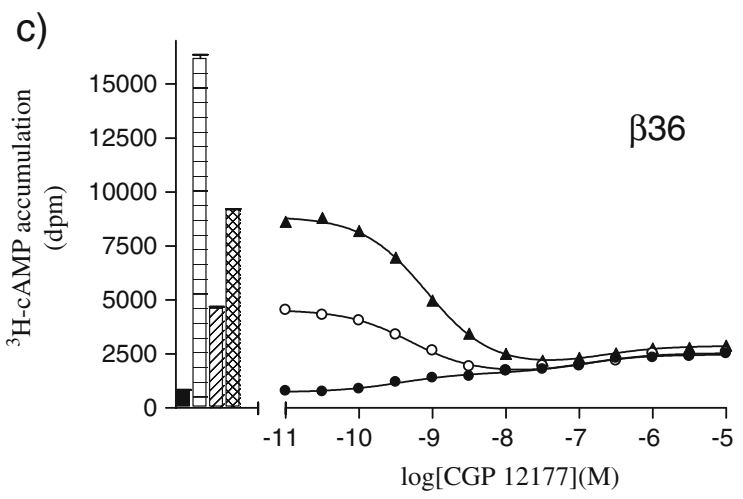

basal

$\mathrm{Q}$ isoprenaline $10 \mu \mathrm{M}$

e cimaterol 3nM

cimaterol 10nM

- CGP 12177

- CGP 12177 + cimaterol 3nM

- CGP 12177 + cimaterol 10nM

d)

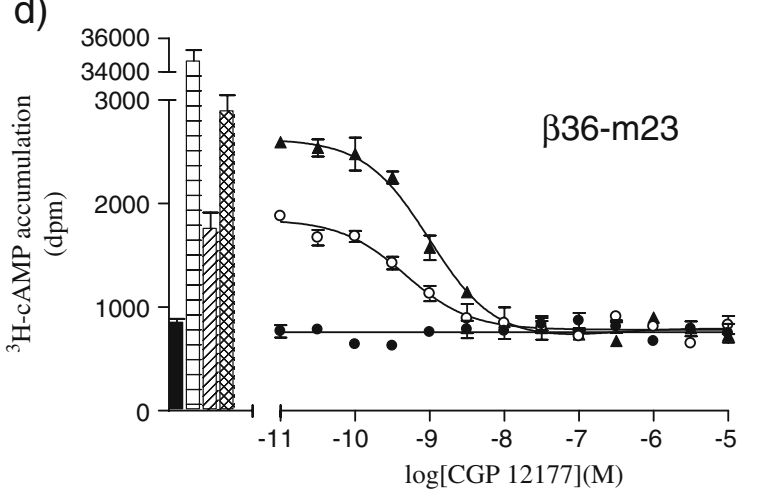

basal

日 isoprenaline $10 \mu \mathrm{M}$

cimaterol 300nM

cimaterol 1000nM

- CGP 12177

- CGP 12177 + cimaterol 300nM

^ CGP 12177 + cimaterol 1000nM

Fig. $10{ }^{3} \mathrm{H}$-cAMP accumulation in response to CGP12177 in a $\mathrm{t} \beta$ trunc cells, $\mathbf{b} \beta 6-\mathrm{m} 23$ cells, $\mathbf{c} \beta 36$ cells and $\mathbf{d} \beta 36-\mathrm{m} 23$ cells in the absence and presence of cimaterol. Bars represent basal ${ }^{3} \mathrm{H}$-cAMP accumulation, that in response to $10 \mu \mathrm{M}$ isoprenaline and that in response to $3,10,30,100,300$ or 1,000 $\mathrm{nM}$ cimaterol. Data points are mean \pm SE mean of triplicate determinations. Each experiment is representative of a four, $\mathbf{b}$ six, $\mathbf{c}$ six and $\mathbf{d}$ four separate experiments 
combined $\beta 36-\mathrm{m} 23$ mutant. Again this could be because the combination of mutations disrupted the secondary site or because the ability of this heavily mutated receptor to stimulate agonist responses is too reduced to be able to examine these partial agonists.

The final evidence for two receptor conformations comes from the inhibition of a catecholamine site agonist response by CGP12177 at lower concentrations than those required to stimulate the CGP12177 agonist response (Baker 2010a; Konkar et al. 2000). When the $\beta 36$ and $\beta 6-\mathrm{m} 23$ mutants were examined alone, this was also the case. Thus CGP12177 at low concentrations inhibited, e.g. the cimaterol response (occurring via the catecholamine site), but higher concentrations of CGP12177 were required to stimulate a CGP12177 agonist response, occurring via the secondary site. This again suggests that both of these mutant receptors exist in two agonist-induced conformations. For the combined $\beta 36-\mathrm{m} 23$ mutant, CGP12177 inhibited the cimaterol response with high affinity, consistent with it binding to the catecholamine site, but the lack of the stimulation in response to CGP12177 once again precluded the demonstration of the secondary site in the $\beta 36-\mathrm{m} 23$ receptor.

\section{Conclusion}

This detailed pharmacological analysis of the effects of the $\beta 36$ deletions and the $\mathrm{m} 23$ thermostabilising mutations alone, and in combination, shows that the final crystallised receptor ( $\beta 36-\mathrm{m} 23)$, whilst having severely reduced ability to activate responses compared to the original $t \beta$ trunc receptor, is still a fully functional receptor, capable of binding agonist and antagonist ligands and activating intracellular agonist responses. The $\mathrm{m} 23$ mutations reduced affinity for agonists, partial agonists and neutral antagonists whilst the $\beta 36$ deletions alone had no effect on ligand affinity. Both sets of changes appeared to reduce the agonist activation of the receptor - the $\beta 36$ deletions most likely by reducing receptor-G-protein activation and the m23 mutations by both reducing ligand affinity and receptor activation (most likely by the increased receptor stability and thus an increased activation energy requirement). Finally, both the $\beta 6-\mathrm{m} 23$ and the $\beta 36$ receptors retained two active agonist-induced receptor conformations similar to that of the original $\mathrm{t} \beta$ trunc receptor, although due to the severely reduced activation ability of the $\beta 36-\mathrm{m} 23$ mutant receptor, this feature is difficult to assess in the final combined mutant.

Thus, the original contention that the $\beta 36-\mathrm{m} 23$ receptor is preferentially in an antagonist-binding conformation appears to be more complex than previously anticipated, not least because only a proportion of the agonists tested showed a marked reduction in affinity compared to the antagonists. The pharmacological characterisation also suggests that the structure of $\beta 36-\mathrm{m} 23$ with cyanopindolol bound may represent the receptor bound with a weak partial agonist. Finally, this work provides a solid foundation for the analysis of further structures of the mutated turkey $\beta$-adrenoceptor with different bound ligands.

Acknowledgements JGB is a Wellcome Trust Clinician Scientist Fellow. We would like to thank June McCulloch, Marleen Groenen and Louise Stone for technical assistance in running the cAMP chromatography columns. We are grateful to Maria Serrano-Vega and Tony Warne for providing cDNA clones of the mutated turkey $\beta$ receptors used to construct the stable cell lines used in this work.

Conflicts of interest CGT is on the Scientific Advisory Board of Heptares Therapeutics Ltd.

Open Access This article is distributed under the terms of the Creative Commons Attribution Noncommercial License which permits any noncommercial use, distribution, and reproduction in any medium, provided the original author(s) and source are credited.

\section{References}

Arch JR (2004) Do low-affinity states of beta-adrenoceptors have roles in physiology and medicine? Br J Pharmacol 143:517-518

Arunlakshana O, Schild HO (1959) Some quantitative uses of drug antagonists. Br J Pharmacol 14:48-58

Baker JG (2005a) Sites of action of $\beta$-ligands at the human $\beta 1$ adrenoceptor. J Pharmacol Exp Ther 313:1163-1171

Baker JG (2005b) The selectivity of $\beta$-adrenoceptor antagonists at the $\beta 1, \beta 2$ and $\beta 3$ adrenoceptors. Br J Pharmacol 144:317-322

Baker JG (2010a) A full pharmacological analysis of the three turkey $\beta$ adrenoceptors and comparison with the human $\beta$-adrenoceptors. PLoS ONE 5(11):e15487. doi:10.1371/journal.pone.0015487

Baker JG (2010b) The selectivity of $\beta$-adrenoceptor agonists at the human $\beta 1, \beta 2$ and $\beta 3$ adrenoceptors. Br J Pharmacol 160:1048-1061

Baker JG, Hall IP, Hill SJ (2003) Agonist actions of " $\beta$-blockers" provide evidence for two agonist activation sites or conformations of the human $\beta_{1}$-adrenoceptor. Mol Pharmacol 63:13121321

Baker JG, Proudman RGW, Serrano-Vega MJ, Tate CG (2008) The effect of the thermostabilising mutations (M23 changes) and intracellular loop amino acid deletions (B36 changes) on whole cell binding to the turkey $\beta$-adrenoceptor expressed in CHO-K1 cells. Available from: http://www.pA2online.org/abstracts/ Vol6Issue4abst065P.pdf.

Balaraman G, Bhattacharya S, Nagarajan V (2010) Structural insights into conformational stability of wild-type and mutant $\beta 1$ adrenergic receptor. Biophys J 99:568-577

Bilezikian JP, Aurbach GD (1973a) A beta-adrenergic receptor of the turkey erythrocyte. I. Binding of catecholamine and relationship to adenylate cyclase activity. J Biol Chem 248:5577-5583

Bilezikian JP, Aurbach GD (1973b) A beta-adrenergic receptor of the turkey erythrocyte. II. Characterization and solubilization of the receptor. J Biol Chem 248:5584-5589

Clarke WP, Bond RA (1998) The elusive nature of intrinsic efficacy. Trends Pharmacol Sci 19:270-276 
Congreve M, Marshall F (2010) The impact of GPCR structures on pharmacology and structure-based drug design. Br J Pharmacol 159:986-996

Donaldson J, Brown AM, Hill SJ (1988) Influence of rolipram on the cyclic-3',5'-adenosine monophosphate response to histamine and adenosine in slices of guinea-pig cerebral cortex. Biochem Pharmacol 37:715-723

Furchgott RF (1966) Advances in drug research. Edited by Harper NJ and Simmonds AB. Academic Press 3: 21-55

Granneman JG (2001) The putative beta4-adrenergic receptor is a novel state of the beta1-adrenergic receptor. Am J Physiol Endocrinol Metab 280:E199-E202

Kaumann AJ, Molenaar P (2008) The low-affinity site of the beta1adrenoceptor and its relevance to cardiovascular pharmacology. Pharmacol Ther 118:303-336

Kenakin T (1999) Efficacy in drug receptor theory: outdated concept or under-valued tool? Trends Pharmacol Sci 20:400-405

Kenakin T (2002) Drug efficacy at G protein-coupled receptors. Annu Rev Pharmacol Toxicol 42:349-379

Konkar AA, Zhu Z, Granneman JG (2000) Aryloxypropanolamine and catecholamine ligand interactions with the $\beta_{1}$-adrenergic receptor: evidence for interaction with distinct conformations of $\beta_{1}$-adrenergic receptors. J Pharmacol Exp Ther 294:923-932

Lowe MD, Lynham JA, Grace AA, Kaumann AJ (2002) Comparison of the affinity of $\beta$-blockers for the two states of the $\beta_{1}$-adrenoceptor in ferret ventricular myocardium. Br J Pharmacol 135:451-461

Molenaar P (2003) The 'state' of beta-adrenoceptors. Br J Pharmacol 140:1-2
Schramm M, Feinstein H, Naim E, Lang E, Lasser M (1972) Epinephrine binding to the catecholamine receptor and activation of the adenylate cyclase in erythrocyte membranes (hormone receptor- -adrenergic receptor-cyclic AMP-turkey). Proc Natl Acad Sci USA 69:523-527

Serrano-Vega MJ, Magnani F, Shibata Y, Tate CG (2008) Conformational thermostabilization of the beta1-adrenergic receptor in a detergent-resistant form. Proc Natl Acad Sci USA 105:877-882

Serrano-Vega MJ, Tate CG (2009) Transferability of stabilizing mutations in $\beta$-adrenergic receptors. Mol Membr Biol 26:385396

Stephenson RP (1956) A modification of receptor theory. Br J Pharmacol 11:5109-5116

Walter M, Lemoine H, Kaumann AJ (1984) Stimulant and blocking effects of optical isomers of pindolol on the sinoatrial node and trachea of guinea pig. Role of beta-adrenoceptor subtypes in the dissociation between blockade and stimulation. Naunyn Schmiedebergs Arch Pharmacol 327:159-175

Warne T, Chirnside J, Schertler GF (2003) Expression and purification of truncated, non-glycosylated turkey beta-adrenergic receptors for crystallization. Biochim Biophys Acta 1610:133-140

Warne T, Serrano-Vega MJ, Baker JG, Moukhametzianov R, Edwards PC, Henderson R, Leslie AG, Tate CG, Schertler GF (2008) Structure of a beta1-adrenergic G-protein-coupled receptor. Nature 454:486-491

Warne T, Serrano-Vega MJ, Tate CG, Schertler GF (2009) Development and crystallization of a minimal thermostabilised $G$ protein-coupled receptor. Protein Expr Purif 65:204-213 